Review

\title{
Updates of Pathogenesis, Diagnostic and Therapeutic Perspectives for Ovarian Clear Cell Carcinoma
}

\author{
Chenchen Zhu1" , Zhihao Xu", Tianjiao Zhang2\#, Lili Qian², Weihua Xiao ${ }^{3,4}$, Haiming Wei3,4, Tengchuan \\ $\mathrm{Jin}^{2}$ and Ying Zhou ${ }^{1,2}$ \\ 1. Department of Obstetrics and Gynecology, Anhui Provincial Hospital, Anhui Medical University, Hefei, 230001, China. \\ 2. Department of Obstetrics and Gynecology, The First Affiliated Hospital of USTC, Division of Life Sciences and Medicine, University of Science and \\ Technology of China, Hefei, Anhui, 230001, China. \\ 3. Division of Molecular Medicine, Hefei National Laboratory for Physical Sciences at Microscale, The CAS Key Laboratory of Innate Immunity and Chronic \\ Disease, School of Life Sciences, University of Science and Technology of China, Hefei, China. \\ 4. Institute of Immunology, University of Science and Technology of China, Hefei, China. \\ \#Co-first authors.
}

$\triangle$ Corresponding authors: Tengchuan Jin, Department of Obstetrics and Gynecology, The First Affiliated Hospital of USTC, Division of Life Sciences and Medicine, University of Science and Technology of China, Hefei, Anhui, 230001, China. E-mail: jint@ustc.edu.cn; Telephone number: +86-0551-63600720; Ying Zhou, Department of Obstetrics and Gynecology, Anhui Provincial Hospital, Anhui Medical University, Hefei, Anhui, 230001, China. E-mail: caddiezy@ustc.edu.cn; Telephone number: +86-0551-62283954.

(c) The author(s). This is an open access article distributed under the terms of the Creative Commons Attribution License (https://creativecommons.org/licenses/by/4.0/). See http:/ /ivyspring.com/terms for full terms and conditions.

Received: 2020.09.17; Accepted: 2021.01.30; Published: 2021.02.22

\begin{abstract}
Ovarian clear cell carcinoma (OCCC) is a special pathological type of epithelial ovarian carcinoma (EOC) and has a high prevalence in Asia without specific molecular subtype classification. Endometriosis is a recognized precancerous lesion that carries 3-fold increased risk of OCCC. Ovarian endometrioid carcinoma, which also originates from endometriosis, shares several features with OCCC, including platinum resistance and younger age at diagnosis. Patients with OCCC have about a 2.5 to 4 times greater risk of having a venous thromboembolism (VTE) compared with other EOC, and OCCC tends to metastasize through lymphatic vesicular and peritoneal spread as opposed to hematogenous metastasis. There is only mild elevation of the conventional biomarker CA125. Staging surgery or optimal cytoreduction combined with chemotherapy is a common therapeutic strategy for OCCC. However, platinum resistance commonly portends a poor prognosis, so novel treatments are urgently needed. Targeted therapy and immunotherapy are currently being studied, including PARP, EZH2, and ATR inhibitors combined with the synthetic lethality of ARIDIA-dificiency, and MAPK/PI3K/HER2, VEGF/bFGF/PDGF, HNFI $\beta$, and PD-1/PD-LI inhibitors. Advanced stage, suboptimal cytoreduction, platinum resistance, lymph node metastasis, and VTE are major prognostic predictors for OCCC. We focus on update pathogenesis, diagnostic methods and therapeutic approaches to provide future directions for clinical diagnosis and treatment of OCCC.
\end{abstract}

Key words: Ovarian clear cell carcinoma, epithelial ovarian carcinoma, endometriosis, targeted treatment

\section{Introduction}

Epithelial ovarian carcinoma (EOC) is the most lethal gynecologic cancer and ranks as the seventh leading cause of cancer-related women's deaths worldwide [1, 2]. In China, ovarian cancer is the third most common gynecologic cancer, ranking behind cervical and uterine cancers. The incidence is higher in rural residents compared with women in urban populations [3]. Ovarian clear cell carcinoma (OCCC) is a specific pathological type of EOC with unique clinical and molecular features. Patients usually present with a large, unilateral pelvic mass, and occasionally have thromboembolic vascular complications or hypercalcemia [4, 5]. The 5-year overall survival (OS) and progression-free survival (PFS) rates are $80 \% \sim 89 \%$ and $56 \% \sim 88 \%$ for International Federation of Gynecology and Obstetrics (FIGO) stages I and II and decrease to 52\% and $25 \%$ for stages III and IV, respectively [6, 7]. 
OCCC patients at late stage tended to have poorer prognosis than those with other histological subtypes of EOC, especially in advanced EOC stages with 1.65-fold higher hazard rate for death [8]. Meanwhile, though serum CA125 levels are frequently mildly or moderately elevated, CA 125 is a poor diagnostic of OCCC [9]. Thus, to improve the ability to diagnose OCCC, novel serological biomarkers are necessary to be identified. Because OCCC displays chemoresistance to platinum, the efficacy of platinum-based chemotherapy is only $20 \%$ to $50 \%$ for OCCC, so more precise therapy is urgently needed $[6,10,11]$. In this review, we summarize current research progress and treatment strategies for OCCC with the aim of aiding the clinical diagnosis and treatment of OCCC.

\section{Epidemiology}

EOC is the most lethal gynecologic cancer, resulting in estimated 239,000 new cases and 152,000 related deaths worldwide every year. In China, it is the tenth most common cancer among women and although the incidence is relatively low $(4.1 / 100,000)$, because China has such a large population, it is estimated that there are still 52,100 and 22,500 cases of women diagnosed with or dead of EOC in 2015, respectively [1-3]. Generally, up to $90 \%$ of ovarian carcinomas are classified as EOCs and they are divided into the following subtypes based on histopathology: high-grade serous carcinomas (HGSC), accounting for $70 \%$ of all EOCs; low-grade serous carcinomas (LGSC), accounting for $<5 \%$; endometrioid, accounting for 10\%; clear cell, accounting for $10 \%$, and mucinous, accounting for $3 \%$, making up more than $95 \%$ of all EOCs [12].

The prevalence of OCCC differs by region. It accounts for $5 \% \sim 10 \%$ of EOC in North America and $12 \%$ in other western countries, but it has a higher prevalence in East Asia, accounting for 25\% 30\% and $10.3 \% \sim 11.6 \%$ of EOCs in Japan and Korea, respectively [13-15]. Due to the highest rate prevalence in Japan, a study revealed that there may be an association between OCCC and ZNF217 amplification among Japanese patients, which may promote neoplastic transformation by promoting cell survival during telomeric crisis [16].Morbidity also differs by race, which is higher in Asians (11.1\%) and lower in black, white, and other populations $(3.1 \%$, $4.8 \%$, and $5.5 \%$, respectively) [17].

\section{Risk factors}

Compared with HGSC, patients with OCCC tend to be diagnosed at a younger age (56 years vs 75 years) and a lower FIGO stage $[18,19]$. The association of obesity and the risk of EOC has been reported, but it is weak in OCCC (odds ratio [OR] $=1.06$ per 5 $\mathrm{kg} / \mathrm{m}^{2}$ ) [2]. In addition, endometriosis is significantly related to the pathogenesis of both ovarian clear cell and endometrioid carcinomas: an increased risk of OCCC $(\mathrm{OR}=3.05)$ and ovarian endometrioid carcinoma $(\mathrm{OR}=2.04)$ among women with endometriosis has been identified by Pearce [20].

Several reproductive and hormonal risk factors are also linked to OCCC, including early menarche, late menopause, low use of oral contraceptives, and low pregnancy rate. This may be because these women have had more ovulations and led to more cellular divisions to repair epithelium after each ovulation, potentially resulting in a greater number of spontaneous mutations and malignant transformations [21-23].

The intrauterine device (IUD) is the most common method of contraception in China, used by about $50 \%$ of all women of reproductive age. The widespread use of IUD and its strong contraceptive effect may have benefit to reduce the incidence of EOC in China. The specific detailed mechanisms between IUD and EOC remain unclear, differences in the type of IUD as well as the usage time of IUD may also make a difference associated to the risk of EOC. $[24,25]$. Pregnancy leads to anovulation and suppression of the secretion of pituitary gonadotropins, which likely has a protective effect on women, particularly for OCCC and ovarian endometrioid carcinomas, with $50 \%$ to $70 \%$ of decreased risk, compared with $20 \%$ reduction for serous carcinoma [2]. Hysterectomy and tubal ligation also have been identified associated with a decreased risk of OCCC, ranging from $30 \%-40 \%$, and the proposed biological mechanisms include limiting the retrograde menstruation and the elevation of inflammatory agents $[2,26,27]$.

OCCC shows little association with family history, and BRCA1/ BRCA2 germline mutations are uncommon in OCCC (2.1\%) [28]. Conversely, ARID1A (which target AT-rich interactive domain 1A) somatic mutations and PIK3CA (phosphatidylinositol-4,5-bisphosphate 3-kinase catalytic subunit alpha) occur frequently in OCCC [29, 30]. The other genetic alterations and possible molecular targets in OCCC are presented in Table 1. In addition, ARID1A and PIK3CA mutations have been found to occur early in tumorigenesis of OCCC [31], Loss of ARID1A expression was usually coincident with PI3K-AKT pathway activation and/or ZNF217 amplification which contributed to the development of OCCC [32]. OCCC is frequently positive for HNF1 $\beta(>95 \%)$, and it is negative for estrogen receptors (ERs) and Wilms Tumor 1 (WT1) in more than $95 \%$ of cases $[12,33,34]$. Recently, Yang et al. detected mutations of MUC4 (28.6\%), MAGEE1 
(19\%), and ARID3A (16.7\%), which have not been previously reported, and MAGEE1 mutation predicts a poorer outcome [35]. Compared with other histological subtypes of EOC, OCCC has a distinct methylation profile, including synchronous gain of promoter methylation for multiple genes in the ER alpha pathway and loss of promoter methylation for numerous genes in the HNF1 pathway [36]. However, further investigation will be required to more precisely outline the functions of these two pathways in this disease.

\section{Molecular Classification of OCCC}

It is known that the four molecular subtypes were identified in HGSC, immunoreactive, differentiated, proliferative and mesenchymal, on the basis of gene expression in the clusters. Winterhoff et al also have validated the transcriptional subtypes on OCCC, they suggested that the OCCC group at advanced stage could use this same transcriptional profiling of HGSC while the OCCC group at early stage may have distinct transcriptional signatures [37]. Similarly, the PROMISE diagnostic algorithm is a reliable surrogate of the molecular group in endometrial carcinoma and ovarian endometrioid carcinoma, including p53, mismatch repair (MMR) protein immunohistochemistry, and DNA polymerase $\varepsilon$ (POLE) exonuclease domain mutation. The role of these markers in OCCC have also been explored, and found that most of OCCC patients have normal p53 expression, only a few of OCCC patients with abnormal p53 expression had adverse features and poor prognosis. However, low frequency of MMR abnormalities and no pathogenic POLE mutations were found in this research. Thus, the role of PROMISE algorithm remains to be elucidated [38]. Since somatic mutations of ARID1A loss have been frequently identified in OCCC, classified OCCC based on ARID1A expression status also helped to distinguish distinct subtype of OCCC. ARID1A-positive tumors were more likely to be histologically of high grades, ER $\beta$-positive, HNF1 $\beta$ negative and E-cadherin-negative than ARID1Anegative tumors, but without difference of age, parity, tumor stage and cancer-specific survival [39]. However, BAF250a encoded by ARID1A is a member of the SWI/SNF complex, aggressive behaviors and poor prognosis were observed in the OCCC losing one or multiple SWI/SNF complex subunits [40]. Two OCCC gene expression subtypes were identified through gene expression profiles: epithelial-like (EpiCC), which is associated with early-stage disease, with a relatively higher rate of gene mutations in the SWI/SNF complex; and mesenchymal-like (MesCC), associated with late-stage and poorer PFS but higher enrichment of immune-related pathway activity as well as preferential drug response to bevacizumab, which could be helpful for prognostic and therapy [41]. Uehara et al. performed single nucleotide polymorphism analysis, and they suggested that expression profiles might be useful for sub-classification of OCCC. Type A was a cluster with broad range and low frequency of copy number alterations (CNAs), type B was a cluster with broad range and low to high frequency of CNAs, and type $C$ was a cluster with focal range and high frequency of CNAs. Endometriosis and early stage were more commonly observed in cluster $\mathrm{A}$ than in clusters B/C, but with lower overall response rate to platinumtaxane chemotherapy [42]. In conclusion, there is no clear and specific molecular typing method suitable for OCCC, it is still required to further investigate novel and reliable molecular subtype classification of OCCC.

\section{Pathogenesis of OCCC}

\section{Atypical endometriosis is a precancerous lesion of OCCC}

It is common in reproductive-age women, occurring in $5 \%$ to $10 \%$ of women at 25 to 35 years old. The association of endometriosis and ovarian cancer has been widely reported $[43,44]$. Between $18 \%$ and $43 \%$ of women with OCCC have a history of endometriosis [19, 45-48], and several studies have demonstrated that this benign disease is a precursor lesion of OCCC and endometrioid carcinoma [21].

Several hypotheses have been advanced to account for the association between endometriosis and ovarian carcinoma. The most well-known of these is the implantation theory, which posits that the viable menstrual endometrial cells were deposited in the pelvic cavity via retrograde menstruation and became the origin of ectopic endometrial tissue. These shed menstrual endometrial cells still capable to attach to the peritoneum, invade, proliferate, and differentiate [49]. The ovary is probably favored seeding sites for endometriosis cells especially in the ovulation sites [21]. Women with endometriosis have been reported to have a two- and three-fold increased risk of OCCC and endometrioid carcinoma, respectively [20]. Inflammation of coelomic epithelial cell-derivatives in the female reproductive tract is a major contributor to malignant transformation in endometriosis-associated OCCC [50]. The microenvironment in endometriosis contains elevated local IL-6 production as well as high oxidative stress which is caused by ions release from disrupted heme [51], and eventually contributes to genomic damage. Some somatic mutations have been detected in paired eutopic and ectopic endometrium, 
and ectopic tissue has a higher mutation burden [52]. Endometriotic lesions commonly carry multiple somatic mutations; atypical endometriosis and co-existing tumors share nearly all of the somatic mutations, such as high expression of HNF1 $\beta$ and driver mutations in ARID1A and PIK3CA, and it is thought that those above mutations occurred early in the malignant transformation of the OCCC [21]. In addition, ARID1A and PIK3CA mutations were found to cooperate to promote tumor growth through sustained IL-6 overproduction, and IL-6 was identified as a physiological target of ARID1A tumor suppressor activity [50]. The schematic diagram of the pathogenesis of OCCC is presented in Figure 1. Moreover, endometriosis was found to be associated with amplification of epidermal growth factor receptor (EGFR) gene and the activation of EGFR plays a critical role in cell proliferation, apoptosis, angiogenesis, and metastasis [16], thus it is necessary to identify whether the amplification of EGFR can trigger the progression from endometriosis to carcinoma. The risk of tumorigenesis in endometriosis is about $1 \%$ among premenopausal women and $1 \%$ to $2.5 \%$ among postmenopausal women $[45,53]$. The risk for 20-year-old women is considered to be 1.00, therefore the risks for women in their 40s and 50s are 3.60 and 10.7, respectively, which indicates that the tumorigenesis of endometrial cysts occurred around menopause [54]. However, Anglesio et al. reported that deep infiltrating endometriosis (DIE) has a low risk of malignant transformation because the somatic driver mutations tend to be confined to the epithelial compartment [55]. Recently, six functional gene clusters in pathogenesis network of OCCC were uncovered by integrated analysis of transcriptomes, including ribosomal protein, eukaryotic translation initiation factors, lactate, prostaglandin, proteasome, and insulin-like growth factor [56]. And Su et al. suggested that complement-activation-alternativepathway may be the crucial dysfunctional immunological pathway in duality for carcinogenesis at all OCCC stages [57]. Nevertheless, further investigation needs to be proceeded about the essential pathogenesis of endometriosis and OCCC.

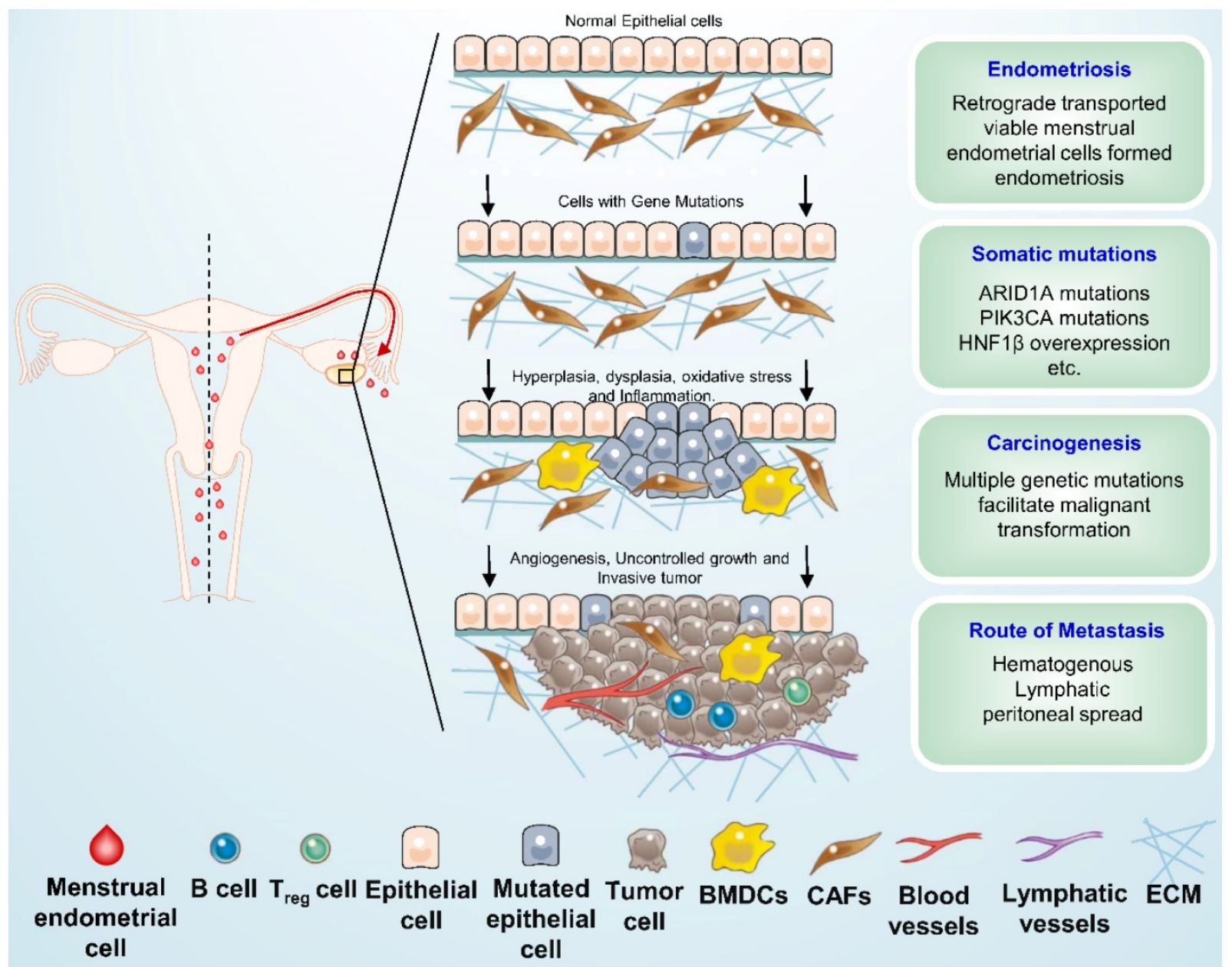

Figure 1. Schematic overview of ovarian clear cell carcinoma development. Shed menstrual endometrium leaves the cavity and retrograde along the fallopian tube to the ovary and into the pelvic or abdominal cavity (red arrow), it may then form endometriosis under multiple factors. Several genetic alterations, such as ARIDIA, PIK3CA mutations and HNF1 $\beta$ overexpression, as well as some microenvironmental change, were suspected to be associated with early carcinogenic events of ovarian clear cell carcinoma. BMDCs: Bone marrow-derived dendritic cells; CAFs: Cancer-associated fibroblasts; ECM: Extracellular matrix. 
Table 1. Genetic alterations and possible molecular targets in ovarian clear cell carcinoma

\begin{tabular}{|c|c|c|c|c|c|c|}
\hline Gene & $\begin{array}{l}\text { Type of } \\
\text { alterations }\end{array}$ & $\begin{array}{l}\text { Frequency } \\
(\%)\end{array}$ & Original function & Therapeutic selection & Drug & Reference \\
\hline ARID1A & $\begin{array}{l}\text { Mutation copy } \\
\text { number loss }\end{array}$ & $40-57 \%$ & $\begin{array}{l}\text { A key component of the SWI-SNF chromatin } \\
\text { remodeling complex; involved in DNA } \\
\text { double-strand break (DSB) repair. }\end{array}$ & $\begin{array}{l}\text { Inhibition of: PARP, EZH2, } \\
\text { ATR, HDAC2, HDAC6, BET, } \\
\text { BCR/ABL/SRC, ROS } \\
\text { induction. }\end{array}$ & $\begin{array}{l}\text { Talazoparib, Olaparib, GSK126, } \\
\text { DZNep, AZD6738, VX-970, } \\
\text { Vorinostat, ACY1215, JQ1, } \\
\text { iBET762, Dasatinib, Elesclomol }\end{array}$ & 29,31 \\
\hline PIK3CA & Mutation & $20-51 \%$ & Activating the PI3K & PI3K, mTOR signal inhibitor & $\begin{array}{l}\text { Buparlisib, copanlisib, } \\
\text { Temsirolimus }\end{array}$ & $30,160,171$ \\
\hline PTEN & $\begin{array}{l}\text { Loss-of-function } \\
\text { mutation }\end{array}$ & $5-8.3 \%$ & $\begin{array}{l}\text { A tumor suppressor that negatively regulates } \\
\text { the PI3K-AKT-mTOR pathway. }\end{array}$ & mTOR signal inhibitor. & Temsirolimus & 5,142 \\
\hline KRAS & Mutation & $9-20 \%$ & $\begin{array}{l}\text { Activation of RAS/RAF/MEK/ERK, } \\
\text { PI3K-AKT-mTOR and RAS/RAF/MAPK } \\
\text { pathways. }\end{array}$ & MAPK signal inhibitor. & - & 29 \\
\hline PPP2R1A & Mutation & $7-15 \%$ & $\begin{array}{l}\text { Impaired PP2A function leading to } \\
\text { uncontrolled cell growth. }\end{array}$ & MAPK signal inhibitor. & - & 30,142 \\
\hline HNF1 $\beta$ & $\begin{array}{l}\text { Hypo-methylation } \\
\text { overexpression }\end{array}$ & $>90 \%$ & $\begin{array}{l}\text { Facilitating glucose uptake and glycolysis to } \\
\text { change cellular metabolism. }\end{array}$ & Glucose metabolism. & Mir-802, metformin & $33,51,184$ \\
\hline BRCA1/2 & Mutation & $6.7 \%$ & DSB repairing deficiency. & PARP inhibitor. & Olaparib & 2,28 \\
\hline
\end{tabular}

Table 2. Comparison of ovarian clear cell and endometrioid carcinoma

\begin{tabular}{|c|c|c|c|}
\hline & & $\begin{array}{l}\text { Ovarian clear cell } \\
\text { carcinoma }\end{array}$ & $\begin{array}{l}\text { Ovarian } \\
\text { endometrioid } \\
\text { carcinoma }\end{array}$ \\
\hline & Prevalence & \multicolumn{2}{|c|}{$5 \%-10 \%$ of epithelial ovarian carcinoma ${ }^{\dagger}$} \\
\hline \multirow[t]{6}{*}{ Similarities } & General classification & \multicolumn{2}{|c|}{ Epithelial ovarian carcinoma } \\
\hline & Molecular subtyping & \multicolumn{2}{|c|}{ Type I } \\
\hline & Origin & \multicolumn{2}{|l|}{ Endometriosis } \\
\hline & $\begin{array}{l}\text { Clinical } \\
\text { characteristics }\end{array}$ & \multicolumn{2}{|c|}{ Diagnosed younger and at an earlier stage } \\
\hline & Prognosis & \multicolumn{2}{|c|}{$\begin{array}{l}\text { Better at early stage, poor at advanced } \\
\text { stage or recurrence }\end{array}$} \\
\hline & Platinum sensitivity & \multicolumn{2}{|c|}{ Low } \\
\hline \multirow[t]{4}{*}{ Differences } & Pathological grade & $\begin{array}{l}\text { Not recommended to } \\
\text { grade }\end{array}$ & $\begin{array}{l}\text { Low, intermediate, } \\
\text { and high }\end{array}$ \\
\hline & $\begin{array}{l}\text { Molecular } \\
\text { characteristics }\end{array}$ & $\begin{array}{l}\text { ARID1A and PIK3CA } \\
\text { gene mutation, } \\
\text { HNF1 } \beta \\
\text { overexpression }\end{array}$ & $\begin{array}{l}\text { PTEN, KRAS, p53, } \\
\text { and } \beta \text {-catenin gene } \\
\text { mutations }\end{array}$ \\
\hline & $\begin{array}{l}\text { Original types of } \\
\text { endometriosis cells }\end{array}$ & Ciliated cell lineage & $\begin{array}{l}\text { Secretory cell } \\
\text { lineage }\end{array}$ \\
\hline & ER and PR & Low expression & High expression \\
\hline
\end{tabular}

†The prevalence of ovarian clear cell carcinoma is $5-10 \%$ of epithelial ovarian carcinoma in America, but with a higher percentage in East Asia.

Abbreviation: ER, estrogen receptor; PR, progesterone receptor.

\section{Comparison of Ovarian Endometrioid Carcinoma and OCCC}

OCCC and ovarian endometrioid carcinoma are 2 pathologic subtypes of EOC, which both likely arise from ovarian or pelvic endometriosis and share some similarities [21, 58]. Table 2 compares the characteristics of these 2 cancers. Both ovarian endometrioid carcinoma and OCCC are identified as Type I tumors which progress in a stepwise manner, whereas HGSC is identified as a Type II tumor with an aggressive phenotype and without specific indications [2]. Under the premise of endometriosis, the risk of OCCC and endometrioid carcinoma increases by 2 3 times [20], but there is no association between survival and endometriosis in either carcinoma [58, 59]. Endometrioid carcinoma, accounting for $5 \%$ to $10 \%$ of all EOCs, is frequently diagnosed when it is at a low grade and early stage with a better prognosis than other pathologic EOC subtypes at the early stage, similar to OCCC $[18,19$, 60]. However, both endometrioid and clear cell carcinomas have low rates of platinum sensitivity, which contributes to their poor prognoses when they present at a late stage or as a recurrence $[48,58]$.

In spite of their similarities, ovarian endometrioid carcinomas and OCCC should be identified as different diseases with unique clinical and molecular characteristics [48, 59, 61]. It is suggested that low- and intermediate-grade endometrioid carcinoma is clinically and biologically different from the high-grade stage [62], which is apparently similar to HGSC, sharing the common feature of p53 mutations and homologous recombination repair deficiencies [63]. However, OCCC is usually not recommended to grade based on morphological features, without prognostic significance [64]. The course of chemotherapy for these 2 cancers is also different, as reflected in the postoperative treatment guidelines issued by the National Comprehensive Cancer Network (NCCN), 2020, version 1 [65]. For ovarian endometrioid carcinoma, observation is optional for patients with stage IA through IC (grade 1) and stage IA through IB (grade 2). Adjuvant chemotherapy or hormone therapy is optional for stages II through IV (grade 1) disease and chemotherapy is considered for stage IC (grade 1) and substages IA through IC (grades 2 and 3) diseases. For patients with grade 2 or 3 endometrioid carcinoma above stage II, the treatment principle is the same as for HGSC. Moreover, OCCC patients showed a higher hazard ratio for death than ovarian endometrioid carcinoma for all stages [8]. As for OCCC, chemotherapy or observation is alternative for substage IA, and adjuvant chemotherapy is recommended for all the other stages in NCCN guideline. In terms of molecular characteristics, a higher frequency of ARID1A mutation has been 
detected in OCCC (46\% to 57\%) than in endometrioid carcinoma (30\%) [47]. Whereas phosphatase and tensin homolog (PTEN), Kirsten rat sarcoma (KRAS), and p53 and $\beta$-catenin gene mutations are more often in ovarian endometrioid carcinoma [59].

\section{The mechanism hypothesis of the difference In OCCC and Ovarian Endometrioid Carcinoma}

To date, it is unclear how endometrioid carcinoma and OCCC, 2 histologically and clinically different tumors, can arise from the same tissue, i.e., the endometrial epithelium of ovarian endometriosis. More and more evidence indicates that OCCC and endometrioid carcinoma possibly originate from different types of endometriosis cells [66]. Kajihara et al. hypothesized that OCCC might originate from already existed endometriosis resulted by retrograde menstruation, and ovarian Mullerian metaplasia might induce tumorigenesis of endometriosisassociated endometroid carcinoma. Another hypothesis was put forward by Cochrane et al. that OCCC is derived from a ciliated cell lineage, whereas endometrioid carcinoma is derived from a secretory cell lineage [67]. It has been suggested that the tumorigenesis of EOC might via 2 modes: a hormoneindependent pathway for OCCC and a hormonedependent pathway for endometrioid carcinoma [68] - on the basis of the low ER expression in OCCC and higher in endometrioid carcinoma. As a result of repeated hemorrhages in endometriosis, the interactions between iron-mediated oxidative stress and the low ER expression are thought to be associated with the tumorigenesis of OCCC [48]. In addition, Davis et al. found that $41.4 \%$ of patients with ovarian endometrioid carcinoma associated with endometriosis had synchronous endometrioid cancer, far more than the $3.8 \%$ that is associated with OCCC [69]. Therefore, they hypothesized that high levels of estrogen leading to the proliferation of endometriosis are implicating in the carcinogenesis of endometriosis.

\section{Clinical characteristics of patients with OCCC}

Patients with OCCC usually examined with a huge unilateral pelvic mass confined to the ovary, accompanied by abdominal pain and swelling symptoms [70] with a mild-to-moderate elevation of serum CA125 [6, 70]. Particularly, they are likely to develop hypercalcemia [4, 5], resulted from the elevated expression of the parathyroid-hormonerelated protein (PTHRP) and the activation of stanniocalcin-1 signaling mediated by IL-6 [71].

In Son's study, nearly $75 \%$ of the cases of OCCC were confirmed to have an association with endometriosis, and endometriosis tend to be diagnosis in women at the age of late 30s and 40s, afterwards, malignant transformation would be completed with a median of 4 years [53]. Endometriosis usually occurs as a unilateral ovarian cyst, OCCC tumors tend to grow intracystically and confined to the ovary until spreading for a long time. They usually have symptoms such as pelvic mass, dysmenorrhea, and dyspareunia, who could be better followed up with frequent hospital visits, while women with other EOC usually have no symptom until they reached advanced stages. These factors mean that patients with OCCC tend be diagnosed with earlier stage in younger age, without ascites or positive peritoneal cytology [48, 72]. Women with no symptom who are diagnosed with OCCC when periodic physical examination are also tend to be at an earlier stage with a smaller tumor size [53]. In ultrasound examinations and computed tomography (CT) of OCCC often reveal a huge, well-defined, unilateral mass with solid components and cyst fluid or necrotic portions [73, 74]. Recently, Stukan et al. found that preoperative lung and intercostal upper abdomen ultrasonography performed in patients with EOC can add valuable information for supradiaphragmatic and subdiaphragmatic metastases [75].

Pathologically the OCCC lesions are usually present as huge masses consist of solid tissue that protrudes into the cyst cavity and commonly displays a combination of papillary, tubulocystic, and solid microscopic patterns. The tumor invades the ovarian interstitium, causing desmoplasia, stromal destruction, hyalinization, desmoplasia and confluence of the epithelial elements. [73]. The presence of clear cells alone could not directly confirm OCCC because clear cytoplasm could also be found in cells of ovarian endometrioid carcinoma and HGSC. OCCC characteristically contains clear or hobnail cells with eccentric, rounded, and bulbous nuclei, multiple complex papillae, densely hyaline basement membrane material, and hyaline bodies. Compared with other types of EOC, the frequency of mitoses is lower (usually < 5 /10 HPFs) [12].

\section{Venous thromboembolism}

Venous thromboembolism (VTE), consist of deep vein thromboses (DVTs) and pulmonary embolisms (PEs), is common in EOCs because of its intrinsic malignancy and time-consuming operations [76, 77]. The incidence of VTE in EOC patients has been reported to be between $1 \%$ and $26 \%$, and the incidences of DVT and PE are 11 18\% and 1 2.6\%, respectively [78, 79] (Figure 2). Patients with OCCC have a higher risk of VTE (15\% to $42 \%)$, PE (4.4\% and $18.6 \%$ ), and DVT (13.2\% and $30.2 \%)$, about 2.5 to 4 times higher than is seen in other subtypes [77, 80-82]. 
VTE is more commonly seen in advanced-stage OCCC $(21.9 \%)$ compared with early-stage $(8.2 \%)$ disease, and PE is more common at advanced stage disease (10-fold). VTEs in patients with advanced OCCC tend to occur in the proximal veins, such as the postcaval, iliac, femoral, and popliteal veins [77]. The elevated IL-6 expression and frequent alteration of tissue factor pathway inhibitor- 2 might increase the risk of VTE in OCCC $[71,83]$. And HNF1 $\beta$ was found associated with glycogen metabolism, including glucose-6-phophatase, and strikingly the blood clotting cascade, including fibrinogen, prothrombin and factor XIII. Positive HNF1 $\beta$ was significantly linked to a 3.0-fold increased risk of clinicallysignificant venous thrombosis among gynecologic carcinomas with cytoplasmic clearing [84].

In terms of timing, most VTE events are found at the initial examination, before the primary surgery $(36.4 \%)$, and developed when the disease reccurs or progresses $(33.3 \%)$. They can also occur following the primary adjuvant chemotherapy period $(18.2 \%)$ and postoperatively $(12.1 \%)[77,85]$. Based on our review and the studies of other researchers, there are some appropriate measurable biomarkers for the increased risk of VTE in ovarian cancer, such as elevated platelet counts, d-dimer levels, white blood cell counts, and CA125 levels, and decreased hemoglobin and

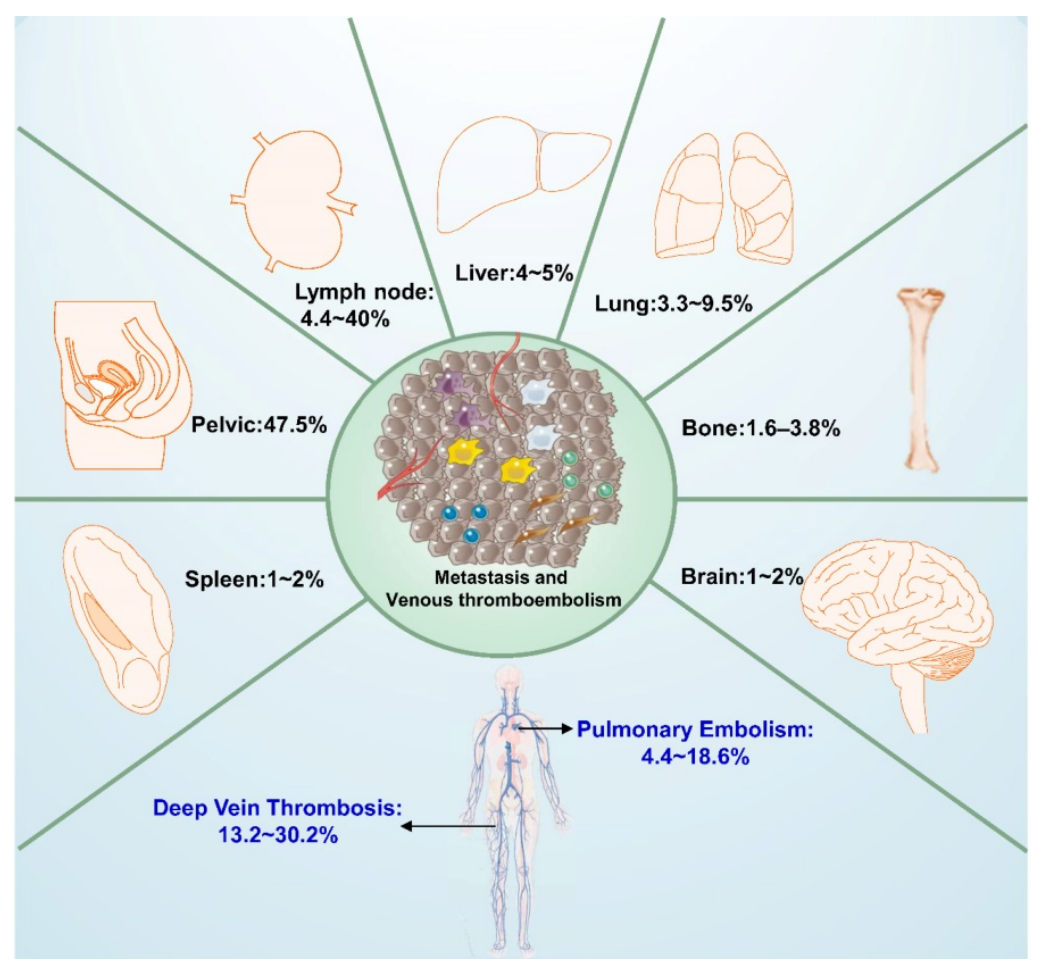

Figure 2. Distributions of metastatic lesions and the commonly complication (venous thromboembolism, VTE) of ovarian clear cell carcinoma. Patients with ovarian clear cell carcinoma especially at advanced stages have high recurrence rates, hematogenous, lymphatic and peritoneal spread are general routes to metastasis. The most frequent sites of metastasis are lymph node and pelvic cavity, rarely in brain, bone and spleen. VTE, consist of deep vein thrombosis (DVT) and pulmonary embolism (PE), is the common complication in epithelial ovarian carcinomas especially in ovarian clear cell carcinoma. albumin levels in the preoperatively; as well as elevated d-dimer levels and decreased albumin levels postoperatively [86-88]. Aggressive operations and chemotherapy are also potential risk factors for VTE [89]. For example, lymphadenectomy can damage the vascular epithelium, promoting the formation of VTE. Therefore, extended thromboprophylaxis should be suggested for patients receiving chemotherapy or having lymphadenectomy $[89,90]$. Because VTEs can occur despite of appropriate prophylaxis, a more aggressive postoperative anticoagulation regimen and prolonged post-discharge VTE prophylaxis should be considered for patients with OCCC [81].

\section{Tumor markers}

\section{Serum cancer antigen 125 (CA125)}

The conventional tumor marker CA125 has long been used in the diagnosis of HGSC. It is elevated in $75.6 \%$ of serous carcinoma cases but in only $57.6 \%$ of OCCC cases [91]. Thus, CA125 is a poor marker for OCCC, with only a mildly elevated baseline value and a frequent incidence of false-negative results $[9,92]$. However, CA-125 levels can be used for predicting advanced stage disease, suboptimal debulking and platinum-resistance with cut-off values of $\geq 46.5$ $\mathrm{U} / \mathrm{mL}, \geq 11.45 \mathrm{U} / \mathrm{mL}$, and $\geq 66.4 \mathrm{U} / \mathrm{mL}$ [93]. Increased CA125 levels after the end of chemotherapy is significantly associated with shorter PFS and OS, so it also can be used as a valid indicator of the prognosis and efficacy of chemotherapy in patients with OCCC [94]. Because there is currently no appropriate biomarker for OCCC, novel diagnostic markers are urgently required to improve early diagnosis and therapeutic stratification of the disease to provide more favorable prognoses and survivability.

\section{Systemic Inflammatory Response (SIR) markers}

Inflammation is a sign of tumor, and tumor-related inflammatory microenvironments promote tumor growth and metastasis. Previous studies have confirmed that chronic inflammation have an effect on tumorigenesis and response to therapy [95, 96], and further affect the prognosis. Platelets also can produce some factors related to tumor growth, invasion and angiogenesis, contributing to protect tumor cells from natural killer cell-mediated lysis and tumor cells metastasis [93]. Several SIR biomarkers are 
found in peripheral blood. For example, the neutrophil-to-lymphocyte ratio (NLR), lymphocyteto-monocyte ratio (LMR), and platelet-to-lymphocyte ratio (PLR) have been reported as potential biomarkers in different cancers [97].

In patients with OCCC, high NLRs are associated with advanced-stage disease, intraperitoneal metastasis, more ascites, elevated CA-125 levels, platinum resistance, and poor prognosis $[9,93,96,98]$. Japanese researchers reported that most patients with early stage OCCC showed complete response to initial treatment that decreased NLR levels, reflecting the improvement in tumor inflammation. In patients who developed a recurrence, NLR was found to be elevated to levels as high as preoperative levels [9]. Therefore, postoperative NLR may predict tumor inflammation in recurrent disease, but it may be affected by certain factors, such as the site of recurrence and the type of previous treatment. Conversely, low LMR is reportedly associated with advanced-stage disease, lymph node (LN) metastases, ascites, and low platinum sensitivity, as well as prognosis, suggesting that low LMR is due to decreased levels of peripheral lymphocytes, which weakens immune surveillance and the response to chemotherapy [96]. PLR levels are not associated with the clinical characteristics of OCCC, but high PLR levels tend to be related to poor OS without significance, and PLR $<205.4$ was an independent factor for the reduced risk of non-complete response [93, 96, 98]. The optimized NLR, LMR, and PLR cut-off values are 2.3 to 3.3, 4.2, and 124 to 165 , respectively $[9,96]$.

\section{Novel OCCC biomarker candidates}

OCCC exhibits increased activity in several signaling pathways that may drive cancer: cell cycle regulation, survival, anti-apoptosis, chemoresistance, metabolism, coagulation, and angiogenesis [7]. Based on the genomic alteration characteristics, it is possible to find some potential sources of diagnostic and prognostic biomarkers for OCCC, including hepatocyte nuclear factor $1 \beta$ (HNF1 $\beta$ ), expressed in almost all cases of OCCC without specific correlation with FIGO stage and is now used as a diagnostic marker to predict ovarian histological subtypes [33, 99]. In immunohistochemistry (IHC), OCCC tends to be positive for CK7 and negative for CK20, hormone receptors ER and PR, WT1, and p53 [12, 34, 100]. In addition, negative a-fetoprotein and CD10 can used to make differential diagnoses, excluding yolk cell tumors and renal cell carcinoma [5]. Left-right determination factor (LEFTY), a novel member of the transforming growth factor- $\beta$ superfamily, may be an excellent OCCC-specific molecular marker with a significantly higher expression in OCCC compared with other subtype of EOC [101]. MiR-509-3-5p, miR-509-5p, miR-483-5p and miR-449a were significantly overexpressed whereas miR-510 and miR-129-3p were significantly downregulated in OCCC compared with HGSC, and miR-182-5p was most overexpressed in OCCC compared with normal ovarian epithelium [102, 103]. In addition, several serum biomarker candidate proteins of OCCC were identified: associated with cell cycle regulation [hepatitis A virus cellular receptor 1 (HAVCR1) and tumor protein D52 (TPD52)], growth factor signaling [insulin-like growth factor binding protein 1 (IGFBP1); KiSS-1 metastasis-suppressor; erb-b2 receptor tyrosine kinase 2 (ERBB2); and fibroblast growth factor receptor 2 (FGFR2)], anti-apoptosis and survival pathways [sialidase 3 (NEU3)], metabolism [r-glutamyltransferase 1 (GGT1)], chemoresistance [napsin A aspartic peptidase (NAPSA), glutathione peroxidase 3 (GPX3); and aldehyde dehydrogenase 1 family, member A1 (ALDH1A1)], coagulation [coagulation factor III (F3); and tissue factor pathway inhibitor 2 (TFPI2)], signaling [lectin, galactosidebinding and soluble, 3 (LGALS3)], and adhesion and the extracellular matrix [cadherin 1, type 1, E-cadherin (epithelial); versican; and laminin, a 5(LAMA5)] [92]. However, additional investigation is required to discover new elevated proteins in peripheral blood or body fluids and confirm their efficacy in the diagnosis or monitoring of OCCC.

\section{Metastasis}

Patients with OCCC, especially those with advanced-stage disease, have high recurrence rates. Hematogenous, lymphatic, and peritoneal spread are general routes for metastasis, but the patterns of OCCC metastasis have not been specifically described $[15,104]$. Between $51.5 \%$ and $66.2 \%$ of recurrent stage I to III OCCC occurs in the peritoneal cavity, even though primary cytoreduction leaves no residual tumor [105]. It is thought that this might be related to the spread of endometriosis into the pelvic peritoneum. Early-stage OCCC, confined in a cyst, commonly remains relatively motionless for a long time, until it pierces the cyst wall, which allows malignant cells to transported through blood vessels or the lymphatics, or to spread into the peritoneal cavity after the cyst ruptures [106]. OCCC tends to metastasize more frequently through the lymphatics and spread into the peritoneal cavity rather than through the blood vessels [107]. The distributions of metastatic lesions of ovarian clear cell carcinoma are presented in Figure 2. In Mueller's study, 4.4\% to 20\% of clinically apparent stage I OCCC had lymph node involved. And this rate will be higher with positive 
cytology or ovarian surface involvement, accounting for as much as $37.5 \%$ of metastases [108]. Patients with localized relapse of OCCC tended to have a favorable prognosis (PFS=19 months, PRS=43 months). The most frequent site of recurrence was the peritoneal cavity, followed by lymph node metastases to the pelvic, para-aortic, and other lymph nodes $(4.4 \%$ to $40 \%)$ and abdominal wall lesions (8.2\%).

Parenchymal organ metastases were occasional in the liver ( $4 \%$ to $5 \%)$, lungs $(3.3 \%$ to $9.5 \%)$ and spleen $(1.6 \%)$, respectively $[15,105,108,109]$. The liver and lung are commonly affected organs, similar to HGSC. Splenic metastasis from EOC is uncommon, accounting for $2 \%$ to $4 \%$ of malignant spleen tumors, and it is seen more frequently in HGSC [110]. Bone metastasis rarely occurs $(1.6 \%$ to $3.8 \%)$ in EOC [111], and it appears to be a late stage of the disease, usually with a survival time of $<4$ months after radiographic diagnosis [111]. However, bone metastases tend to be more common in OCCC than in HGSC, according to Jenison's study, accounting for $16 \%$ of OCCC metastases compared with no cases of bone metastases in the group of patients with HGSC [112]. This is consistent with prior research, which reported that bone metastases are rare in HGSC [113, 114]. Metastasis to the brain is also rare, accounting for only $1 \%$ to $2 \%$ of all EOC and most commonly seen in HGSC, with a median OS of 8.2 months [115]. Brain metastasis has rarely been reported in OCCC, with only 13 cases reported as of this writing [116-119]. Surgery, whole-brain radiation, stereotactic radiosurgery, gamma knife surgery, and chemotherapy can be used for metastatic brain lesions, but the bloodbrain barrier could prevent effective drug delivery, which a great obstacle to chemotherapy [119].

\section{Treatment}

Standard staging surgery or optimal cytoreduction combined with systemic chemotherapy is the usual primary therapeutic strategy for OCCC, according to the NCCN guidelines (version 1.2020). The preferred regimens of postoperative systemic therapy are paclitaxel 175/carboplatin (paclitaxel 175 $\mathrm{mg} / \mathrm{m}^{2}$ iv. followed by carboplatin AUC 5-6 iv. Day1, repeated every 21 days for 3 to 6 cycles) for stage I OCCC. For stage II to IV OCCC, post-operative treatment is the same as for high-grade serous, endometrioid (grade 2, 3) carcinomas and carcinosarcoma: paclitaxel 175/carboplatin and paclitaxel/carboplatin/bevacizumab + maintenance bevacizumab (paclitaxel $175 \mathrm{mg} / \mathrm{m}^{2}$ iv. followed by carboplatin AUC 5-6 iv., and bevacizumab $7.5 \mathrm{mg} / \mathrm{kg}$ iv. Day 1, repeated every 21 days for 3 to 6 cycles, with continued bevacizumab for up to 12 additional cycles). The same regimen is also recommended for stage II to IV OCCC (ICON-7 and GOG218) [65]. However, global clinical trials are needed personalized medicine for rare tumors, so that the use of bevacizumab as first-line chemotherapy for OCCC is still controversial which needs to be further validated.

\section{Primary Cytoreductive and Staging Surgery}

Staging surgery or cytoreduction is recommended for patients with OCCC in every stage. Complete surgery with no gross residual macroscopic (R0) disease is the most important prognostic factor for OCCC. Significantly poorer prognosis has been observed even with small-volume residual disease. The prognosis was reported to be significantly better in the complete resection group compared with the groups having residual tumor diameters both greater than and less than $1 \mathrm{~cm}$ following the initial surgery [120]. So that effort should be made to the greatest extent to remove all gross disease during an operation of OCCC. Two clinical trials, CHORUS and EORTC55971, compared the outcomes of patients with advanced EOC who had primary cytoreduction and NACT (neoadjuvant chemotherapy) + interval cytoreduction and reported noninferior survival for patients treated with NACT [121, 122]. However, because the incidence of OCCC was low $(1.5 \%$ to $6.0 \%$ ) in both trials and because OCCC is inherently resistant to platinum, to apply these results needs more investigation specific to OCCC.

Systematic pelvic and para-aortic lymphadenectomy is important to accurately determine disease stage, provide prognostic information, and guide adjuvant therapy [15]. Although these procedures have been widely used in EOC, the efficacy of lymphadenectomy is ambiguous in OCCC. It has been reported that systematic lymphadenectomy benefit to longer OS, and that the number of lymph node excision is a potential prognostic predictor for early OCCC, with PFS of the group that had $\geq 35$ lymph nodes removed significantly better than the PFS of the group that had $<35$ lymph nodes removed [123, 124]. However, an Italian multicenter trial illustrated that lymphadenectomy increased OS only in advanced OCCC but had no effect on survival in patients with early disease [125]. Suzuki et al. also reported that there was no difference in survival for early OCCC with or without lymphadenectomy [126]. It is plausible to limit the extent of lymph node dissection in selected cases, considering that the positive lymph nodes exist in only a minority of cases and that lymphadenectomy can increase the potential for complications, both intraoperatively (vascular and neurologic injury) and postoperatively (lymphedema 
and the formation of lymphocysts) [108]. Further study should be performed to verify the efficacy of lymphadenectomy on OCCC.

\section{Secondary Cytoreductive Surgery}

The efficacy of surgery for recurrent EOC has been debated for a long time. The DESKTOP III trial was conducted among platinum-sensitive recurrent EOC to compare secondary cytoreductive surgery plus chemotherapy with chemotherapy alone, and showed that the former resulted in an improvement PFS of 5.6 months, but this study only included a small number of patients with OCCC $(<5 \%)$ [127]. Kajiyama demonstrated that patients with recurrent OCCC who had re-cytoreduction had median PFS and post-recurrence survival times of 10.9 and 21.2 months, respectively, longer than the survival times of patients who only had salvage chemotherapy, but without statistic significance [105]. Other studies found that patients with a solitary recurrence or metastasis to other sites that could be resected showed improved post-recurrence survival [105, 128]. Thus, the choice of treatment for patients with recurrent OCCC should be based on the performance status, site of recurrence, and platinum-sensitivity.

\section{Fertility-Sparing Surgery (FSS)}

Approximately $12 \%$ of EOC occurs in patients of reproductive age [129], so for patients desiring to remain fertile, fertility-sparing surgery that only perform unilateral salpingo-oophorectomy to preserve the unaffected ovary and the uterus, should be considered. However, the NCCN guidelines do not recommend FSS for stage IA to IC OCCC but indicate that FSS is optional for patients hoping to preserve fertility with apparent early-stage disease and/or low-risk tumors, such as early-stage invasive epithelial tumors, low malignant potential lesions, malignant germ cell tumors, mucinous tumors, or malignant sex cord-stromal tumors. However, a Gynecologic Cancer Inter Group (GCIG) consensus review indicated that FSS should not be considered for OCCC beyond stage IC [15]. Previous researches have assessed the outcomes of FSS among cases of stage I OCCC. Based on the National Cancer Institute's Surveillance, Epidemiology, and End Results (SEER) data, Nasioudis considered FSS was safe for stage IA to IC OCCC, and the survival was not affected [130]. A few studies illustrated similar conclusions, reporting that patients with stage IA IC1 OCCC were more suitable to receive FSS, and FSS would not lead to a poorer prognosis [129, 131, 132]. To determine whether the indications for FSS can be extended to stage I OCCC or not, further clinical research is needed especially for patients with stage
IA to IC1 OCCC strongly wishing to have babies in the future [129].

\section{Adjuvant Chemotherapy}

Compared with other subtypes of EOC, patients with OCCC tend to be less sensitive to conventional platinum-based chemotherapy, resulting in poor outcomes. Only $11 \%$ to $27 \%$ of patients with OCCC respond to a platinum-based chemotherapy, while patients with HGSC had a significantly higher response rate of $73 \%$ to $81 \%$ [10, 92]. Previous researches have indicated some mechanisms associated with this resistance, such as drugs accumulate decreasing, drugs detoxicate increasing, and DNA repair increasing. Adenosine 5 'triphosphate (ATP)-binding cassette (ABC) transporters enhance drug efflux and decrease drug accumulation, and they are important multidrug resistance factors [4]. Drug activity in cell could also be reduced by drug detoxification systems. Studies have shown that the cell detoxification effect of the glutathione system is involved in the metabolism of a variety of cytotoxic drugs. Glutathione peroxidase 3 (GPx3), glutaredoxin (GLRX), and superoxide dismutase (SOD2) might result in chemotherapy resistance, which are highly expressed in OCCC [133]. Two key genes, ERCC1 (excision repair cross-complementing rodent repair deficiency, complementation group 1) and $\mathrm{XPB}$ (xeroderma pigmentosum group B), highly expressed in OCCC, might be involved in nucleotide excision repair which related to chemotherapeutic resistance [134]. DNA mismatch repair systems (MMR) are also associated with the sensitivity of DNA-damaging agents. Germline mutations of hMLH1 or hMSH2, or inactivation of somatic MMR gene usually result in loss of MMR [135]. In addition, overexpression of EGFR, HNF1 $\beta$, and HER2 is involved in chemoresistance and poor outcomes [4]. The low proliferation activity of OCCC is also thought to be associated with chemoresistance [136].

However, platinum-based chemotherapy is still used in OCCC patients with no better choice. In addition, the effect of adjuvant chemotherapy on early-stage cancer is controversial. Several studies indicated that postoperative chemotherapy is unnecessary for patients with stage I OCCC because it does not improve survival [7, 58, 137, 138]. Considering the prognosis for early-stage OCCC is good, adjuvant chemotherapy should be considered for these patients. In addition, 3 6 cycles of adjuvant chemotherapy are suggested for OCCC, though some studies have found that the duration of chemotherapy does not affect the prognosis for early-stage, nonserous tumors $[120,139,140]$. 


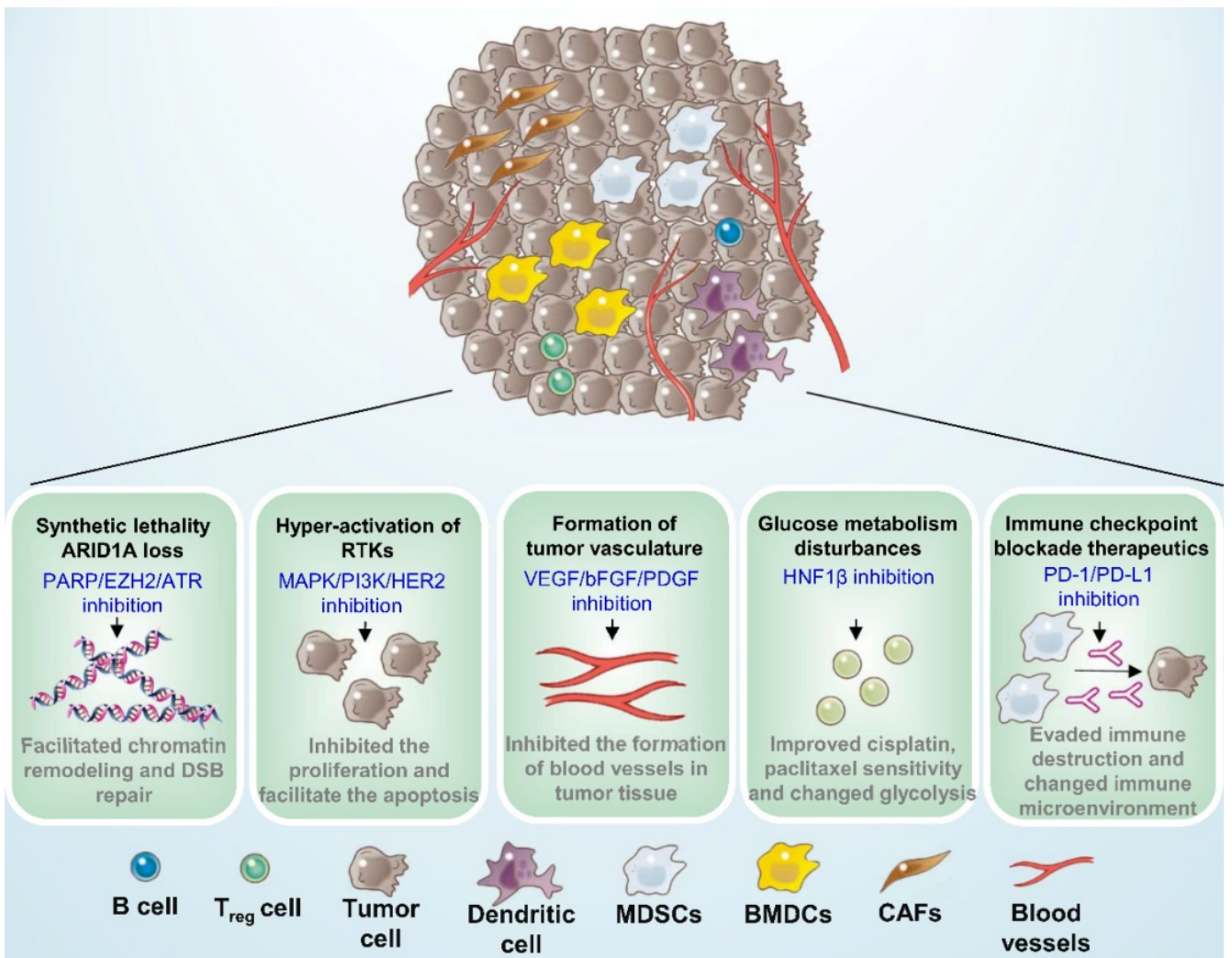

Figure 3. Potential therapeutic targets for ovarian clear cell carcinoma. Five mechanisms of potential therapeutic target have been characterized in ovarian clear cell carcinoma, including synthetic lethality with ARIDIA loss, suppression of hyper-activation of RTKs, formation of tumor vasculature and glucose metabolism disturbances, and immune checkpoint blockade therapeutics. MDSCs: Myeloid-derived suppressor cells; BMDCs: Bone marrow-derived dendritic cells; CAFs: Cancer-associated fibroblasts.

The response rate to second-line chemotherapy for recrudescent or refractory OCCC is much lower than other EOCs, even among patients who are sensitive to primary chemotherapy, with a response rate of less than 10\% [10]. OCCC with ARID1A-loss have been found to be more sensitive to gemcitabine than those without in vitro, which means OCCC with ARID1A deficiency might potentially benefit from a gemcitabine regimen for salvage therapy, with a response rate of between $22 \%$ and $60 \%$ [141, 142]. It has been reported that some other regimens have demonstrated well efficacy, including paclitaxel/carboplatin, etoposide/platinum, and irinotecan/platinum, but they only increase PFS by approximately 6 months $[143,144]$. OCCC is an extremely chemo-resistant carcinoma, especially for patients with recurrent or refractory disease. Therefore, more effective therapies are urgent needed.

\section{Novel Therapeutic Strategies}

\section{Targeting the ARIDIA gene}

ARID1A is a key component of the SWI-SNF chromatin remodeling complex and is also associated DNA double-strand break (DSB) repair. ARID1A loss occured in $40 \%$ to $57 \%$ of patients with OCCC and has been identified as an early event in the progression of malignancy, portending a poor prognosis [30]. The rationale for targeting ARID1A-defective OCCC is based on synthetic-lethal approaches that can be exploited and clinically combined with targeted DNA repair proteins Poly-ADP Ribose Polymerase (PARP) or Ataxia-Telangiectasia Mutated and Rad3-related protein kinase (ATR), as well as with epigenetic factors such as enhancer of zeste homolog 2(EZH2), histone deacetylase (HDAC), or bromodomain and extra terminal (BET), shown in the Table 1 and Figure 3.

PARP plays an important role in single-strand DNA break repair, and inhibition of PARP plays a synthetically lethal effect, with deficient DSB repair caused by BRCA mutations [145]. However, BRCA1 and 2 mutations are only observed in $2.1 \%$ of patients with OCCC, so single-agent PARP inhibitor therapy could benefit only a minority of these patients $[2,28]$. Because ARID1A facilitates efficient repair of DSB, Shen et al. have found that ARID1A deficiency could potentially sensitize the response of cancer cells to PARP inhibitors in vitro and in vivo, suggesting that PARP inhibitors might be a potential therapy for ARID1A-deficient OCCC through its synthetically lethal effect [146]. In addition, ARID1A deficiency results in topoisomerase $2 \mathrm{~A}$ and cell-cycle defects, increasing the dependence on ATR checkpoint activity. Therefore, ATR inhibitors are also expected 
to treat OCCC with of ARID1A deficiency [147]. VX-970, the ATR inhibitor, has been confirmed to more than a 3-fold increased effect in multiple ARID1A-deficient cancer lines, including several OCCC cell lines [147]. However, there is still no clinical trial assesses the effects of PARP or ATR inhibitors in women with OCCC, it deserves further exploration [148].

Disruption of epigenetic chromatin remodeling has an effect on driving oncogenesis of tumors that lack genomic instability. EZH2, an enzymatic component of the Polycomb Repressive Complex 2 (PRC2), regulates transcription and involves in synthetic lethal effect with ARID1A, confirmed in ovarian cancer cells and mouse models [149, 150]. However, first-generation EZH2 inhibitors (DZNep) have demonstrated toxicity in vivo, and 2 new EZH2 inhibitors are undergoing clinical trials [151]. HDAC2 interacts with EZH2 depending on ARID1A status and acts as a co-inhibitor of EZH2 to inhibit the tumor suppressor genes expression such as PIK3IP1. ARID1A-deficiency improved the sensitivity to inhibitors of pan-HDAC, for example SAHA, reducing the growth and ascites of the OCCC with ARID1A deficiency in both vivo and vitro, significant improvement of survival of mice [152]. It has been reported that vorinostat, which inhibits HDAC2, a binding partner of the PRC2 complex, reduced proliferation and facilitated apoptosis in ARID1Adeficient OCCC cells [152]. Inhibition of HDAC6 was also effective in several OCCC cell lines with ARID1A deficiency $[153,154]$. Recently, knockdown of the BET has been found to establish specific lethality in OCCC cell lines with ARID1A deficiency, inhibitors such as JQ1 and iBET762 are under clinical investigation [155]. Dasatinib, a multikinase inhibitor, increased more than 2-fold sensitivity in OCCC cells with ARID1A deficiency compared with wild-type cells [156], and its therapeutic efficacy has also been confirmed in a xenograft model [157]. Dasatinib is considered to be the synthetic lethality partner of OCCC with ARID1A deficiency, and the trial (GOG 283) investigating its efficacy on persistent or recurrent OCCC is still ongoing [156].

Recently, alteration of cellular metabolism in ARID1A deficient cells was put forward as a novel therapy. SLC7A11, encoding a subunit of cystine/ glutamate transporter XCT, is poorly expressed in OCCC cells with ARID1A deficiency, leading to the low level of GSH and high level of reactive oxygen species (ROS). Cystine enters the cell through XCT complex to exchange glutamate and soon reduced to cysteine by thioredoxin reductase (TRXN) producing thioredoxin $(\mathrm{TXN})$. Then cysteine and glutamate will be used to produce reduced glutathione (GSH) using $\gamma$-glutamate cysteine ligase (GCL). Both GSH and TXN have functions of controlling ROS levels and preventing cell death. The balance between GSH and ROS is broken in ARID1A-deficient OCCC cells, and these cells are sensitive to the inhibitors of TRXN and GSH, such as auranofin, APR-246, or buthionine sulphoximine (BSO), leading to the accumulation of ROS and decrease the antioxidant capacity, triggering cell death $[158,159]$. However, further research about GSH inhibitors should be developed in vivo and vitro, as well as combined with other target therapies to achieve better curative efficacy.

\section{Downstream Pathways of Receptor Tyrosine Kinases}

Receptor tyrosine kinases (RTKs) are receptors located on the surface of cells and have an important effect on proliferation, migration, differentiation, metabolism, and survival. Both the PI3K/AKT/ mTOR (phosphoinositide 3-kinase/AKT/mammalian target of rapamycin) and EGF/RAS/MAPK (epidermal growth factor/RAS/mitogen-activated protein kinase) are downstream RTK pathways [160]. PI3K/AKT and RTK/RAS signalling pathways activation have been proved to be involved in higher survival rate for OCCC patients [161, 162]. Some genetic mutations and key components are associated with these pathways that could be potential therapeutic targets in OCCC are listed in Table 1 and Figure 3, including PIK3CA, PTEN, and the human epidermal growth factor receptor 2 (HER2) and MET (also known as hepatocyte growth factor receptor, HGFR).

The PI3K/AKT/mTOR pathway plays a central role to regulate cell proliferation, adhesion, apoptosis, G1 cell cycle progression, carcinogenesis, and metastasis, and activation of this pathway has an important effect on the pathogenesis of OCCC [159, $160,163,164]$. Inhibitions of this pathway have been suggested to be a promising therapeutic approach [29]. The PI3K inhibitor $\mathrm{CH} 51327$ and the AKT inhibitor MK2206 are indicated to decrease growth of ovarian cancer cells $[165,166]$. Perifosine, a kind of AKT inhibitor, showed significant anti-tumor activity in OCCC that had acquired resistance to bevacizumab or cisplatin, inhibit proliferation, and induce apoptosis of OCCC cells, suggesting that AKT is a promising therapeutic target especially for recurrent OCCC after platinum-based or bevacizumab chemotherapy [167]. Also, compared with HGSC, mTOR is activated in OCCC more frequently $(86.6 \%$ vs $50 \%$ ) [163], inhibiting mTOR can overcome OCCC resistance to cisplatin or trabectedin in vitro [51].

RAD001 (everolimus), an mTOR inhibitor, is a promising agent for the treatment of OCCC both as a front-line treatment and as a salvage treatment for 
recurrence after platinum-based chemotherapy, because the anti-tumor effect of RAD001 was greater in cisplatin resistant cell-derived tumors than in cisplatin sensitive cell-derived tumors [164]. However, RAD001 would induce mTORC2-mediated AKT activation and gain resistance in RAD001sensitive OCCC cells. Furthermore, inhibition of mTORC2 during RAD001 treatment could prevent OCCC cells from acquiring resistance to RAD001 and enhance the anti-tumor effect. Thus mTORC2targeted therapy may be efficacious in a front-line setting as well as for second-line treatment of recurrent disease developing after RAD001 [168]. Recently, it has been reported that overexpression of miR-100 can inhibit mTOR signaling and enhance sensitivity to the RAD001; miR-22 is also a candidate tumor suppressor in OCCC that influence $\mathrm{PI} 3 \mathrm{~K} / \mathrm{AKT} / \mathrm{mTOR}$ signaling through direct and indirect effects at multiple points in the pathway[169]. However, a clinical trial of the mTOR inhibitor temsirolimus has shown unsatisfactory effects (Table 3) [170]. ARID1A-deficient OCCC often has PI3K/ AKT signaling pathway mutations, including gaining-function mutations of the PIK3CA oncogene or losing-function mutations of PTEN [5, 142, 171], and both mutations are considered early events in OCCC carcinogenesis [31]. Therefore, PI3K pathway activation and ARID1A deficiency may be synthetically lethal, but requiring further investigation [148].

For the RAS-RAF-MAPK pathway, most mutations influencing this pathway occurred in the first signaling element, KRAS [29]. Mutations in oncogenic KRAS often coexist with PPP2R1A (encoding serine/threonine protein phosphatase 2 scaffold subunit alpha), and thay have been observed in $9 \%$ to $20 \%$ and $7 \%$ to $15 \%$ of cases of OCCC, respectively, activating the MAPK signaling pathway [30, 142]. This suggests that potential therapeutic efficacy of inhibiting the RAS signal transduction downstream in OCCC could be achieved by using MAPK and PI3K/AKT/mTOR inhibitors.

HER2, an RTK playing an important role in the regulation of proliferation, immigration and differentiation of OCCC, is overexpressed in $14 \%$ to $42.9 \%$ of cases of OCCC [31]. Trastuzumab has been reported to significantly and dose-dependently inhibit tumor growth in HER2-overexpressing OCCC cell lines in mice, prolonging their survival [163, 172]. However, a clinical study of the efficacy of single-agent trastuzumab found a disappointing response rate of $7.3 \%$, with only 3 cases of complete or partial response (PR) out of the 7 cases of recurrent OCCC with HER2-overexpression [173]. Therefore, combination chemotherapy with trastuzumab, which has obviously benefited patients with breast and gastric cancers, should be further investigated in patients with HER-2 overexpressed OCCC [51]. MET is another RTK that participates in both MAPK and PI3K pathways and is involved in promoting proliferation and invasion in various tumors [31]. MET has been found to be overexpressed in $14 \%$ to $37 \%$ of cases of OCCC, associating with a poor prognosis [51, 174]. MET inhibitors have been reported to significantly inhibit the proliferation and facilitate the apoptosis of OCCC cell lines and to suppress tumor growth in xenograft models [175]. However, a study of the MET inhibitor cabozantinib in 13 cases of recurrent OCCC (Table 3) did not demonstrate any clinical benefits (response rate $=0 \%$ ) [176].

\section{Targeting Angiogenesis}

Anti-angiogenic drugs inhibit blood vessels formation by inhibiting vascular endothelial growth factor (VEGF), basic fibroblast growth factor (bFGF), and platelet-derived growth factor (PDGF) [29]. VEGF is usually expressed in approximately $90 \%$ of cases of OCCC both in early and advanced stage, significantly higher in cisplatin-refractory OCCC cells, and related to poor prognosis. Inhibitors of VEGF or VEGF receptors (VEGF-R) have been the typical therapy for EOC [142, 177, 178], with a high response rate combined with chemotherapy regimen of carboplatin and paclitaxel (Figure 3) [179]. To date, clinical trials of bevacizumab (targeting VEGF), sunitinib (targeting VEGF-R and PDGF-R), and carbonatitic (targeting VEGF-R and MET) have been completed but have shown unsatisfactory effects (Table 3). However, receiving ENMD-2076, a multi-target kinase inhibitor of Aurora kinase-A, VEGFR, and FGFR, patients with ARID1A-deficient OCCC had a significantly higher 6-month rate of PFS ( $33 \%$ vs $12 \%)$, compared with the ARID1A-positive cases in a phase II clinical trial [180]. Nintedanib is a new, effective, triple-angiokinesis inhibitor which is mainly targeted at VEGFR 1-3, FGFR 1-3, and PDGF receptors $\alpha$ and $\beta$. A clinical trial of NiCCC (ENGOT-GYN1) is also ongoing [181]. In a recent preclinical research, axitinib, an inhibition of VEGFR signals, showed significant anti-tumor effects in OCCC cells associated with cell proliferation, apoptosis and migration in vivo and in vitro. However, the effects of axitinib were not promising against drug-resistant EOC, so the clinical effects of combination therapies of axitinib with other target agents and immunotherapy are still need to be identified [182]. 
Table 3. Clinical trials of target therapy for patients with ovarian clear cell carcinoma

\begin{tabular}{|c|c|c|c|c|c|c|}
\hline $\begin{array}{l}\text { Therapeutic } \\
\text { targets }\end{array}$ & Drug & Trial name & Patients type & $\begin{array}{l}\text { No. of } \\
\text { OCCC }\end{array}$ & Response summary & Reference \\
\hline $\begin{array}{l}\text { Synthetic lethality } \\
\text { ARID1A loss }\end{array}$ & Dasatinib & GOG 283 & Persistent or recurrent OCCC & - & On-going (NCT02059265) & 156 \\
\hline mTOR & $\begin{array}{l}\text { Temsirolimus } \\
+ \text { paclitaxel } \\
\text { +carboplatin }\end{array}$ & GOG 268 & Stage III to IV OCCC & 90 & $\begin{array}{l}\text { 12-months PFS rate }=54 \% \text {, not significantly different than } \\
\text { historical controls; Most common grade } 3-4 \text { adverse events } \\
\text { were cytopenia; Otherwise well tolerated. }\end{array}$ & 170 \\
\hline VEGFR, PDGF & Sunitinib & GOG 254 & Persistent or recurrent OCCC & 30 & $\begin{array}{l}\text { Response rate of } 6.7 \% \text {, } \\
\text { Median PFS=2.7 months, OS=12.8 months } \\
\text { Grade } 4-5 \text { adverse events: thrombocytopenia (5), anemia (2), } \\
\text { acute kidney injury (1), stroke (1), and allergic reaction (1). }\end{array}$ & 177 \\
\hline $\begin{array}{l}\text { VEGFR, PDGFR, } \\
\text { FGFR }\end{array}$ & Nintedanib & $\begin{array}{l}\text { NiCCC (ENGOT- } \\
\text { GYN1) }\end{array}$ & Persistent or recurrent OCCC & - & On-going (NCT02866370) & 181 \\
\hline $\begin{array}{l}\text { MET, RET, } \\
\text { VEGFR2 }\end{array}$ & Cabozantinib & NRG-GY001 & Persistent or recurrent OCCC & 13 & $\begin{array}{l}\text { Response rate of } 0 \% \text {; } \\
\text { Median PFS }=3.6 \text { months, OS }=8.1 \text { months; } \\
\text { Single patient with lethal thromboembolic event, possibly } \\
\text { treatment related. }\end{array}$ & 176 \\
\hline $\begin{array}{l}\text { Aurora A, VEGFR, } \\
\text { FGFR }\end{array}$ & ENMD-2076 & $\begin{array}{l}\text { A Study of } \\
\text { ENMD-2076 in } \\
\text { OCCC }\end{array}$ & Persistent or recurrent OCCC & 40 & $\begin{array}{l}\text { Response rate of } 7.5 \% \text { higher } 6 \text {-month PFS rate in ARID1A } \\
\text { protein loss than ARID1A IHC positive population ( } 33 \% \text { vs. } \\
12 \% \text { ); Adverse events were well tolerated. }\end{array}$ & 180 \\
\hline VEGF & $\begin{array}{l}\text { Bevacizumab } \\
\text { +Carboplatin } \\
\text { +Paclitaxel }\end{array}$ & JGOG 3022 & $\begin{array}{l}\text { Stage III to IV epithelial } \\
\text { ovarian/fallopian tube/ } \\
\text { primary peritoneal cancer. }\end{array}$ & 11 & $\begin{array}{l}\text { Response rate of } 63.6 \% \text {; } \\
\text { Median PFS= } 12.3 \text { months, } 1 \text {-year PFS= } 50.5 \text { months; } \\
\text { Adverse events were well tolerated. }\end{array}$ & 179 \\
\hline PD-L1 & Avelumab & $\begin{array}{l}\text { JAVELIN Solid } \\
\text { Tumor Trial }\end{array}$ & $\begin{array}{l}\text { Recurrent or refractory stage } \\
\text { III-IV ovarian cancer. }\end{array}$ & 2 & $\begin{array}{l}1 \text { had a partial response and the other had an } \\
\text { immune-related partial response. }\end{array}$ & 189 \\
\hline $\begin{array}{l}\text { PD-L1, PARP or } \\
\text { VEGFR }\end{array}$ & $\begin{array}{l}\text { Durvalumab+ } \\
\text { Olaparib or } \\
\text { Cediranib }\end{array}$ & NCT02484404 & $\begin{array}{l}\text { Recurrent or metastatic } \\
\text { measurable solid } \\
\text { malignancies. }\end{array}$ & 1 & $\begin{array}{l}\text { This patient received durvalumab + cediranib exhibited a } \\
\text { partial response. }\end{array}$ & 190 \\
\hline PD-1 & Pembrolizumab & KEYNOTE-100 & Recurrent ovarian cancer. & 19 & Response rate of $15.8 \%$; Adverse events were well tolerated. & 191 \\
\hline PD-1 & Nivolumab & NCT02484404 & $\begin{array}{l}\text { Advanced or relapsed, } \\
\text { platinum-resistant ovarian } \\
\text { cancer. }\end{array}$ & 2 & 1 case of complete response. & 192 \\
\hline PD-1/PD-L1 & Durvalumab & MEDI-4736 & Persistent or recurrent OCCC. & 46 & On-going (NCT03405454). & 193 \\
\hline
\end{tabular}

Abbreviation: OCCC, ovarian clear cell carcinoma; PFS, progression-free survival; OS, overall survival; IHC, immunohistochemistry.

\section{Targeting Hepatocyte Nuclear Factor-1 $\beta$}

There is severe oxidative stress in the endometriotic cysts microenvironment, so the epithelial cells suffer from more cellular and DNA damage and develop spontaneous malignant transformation [183]. A transcription factor, hepatocyte nuclear factor-1 $\beta$ (HNF1 $\beta$ ), is expressed in more than $95 \%$ of cases of OCCC and is regarded as a biomarker of OCCC [33]. HNF1 $\beta$ facilitates proliferation of OCCC cells but inhibits their invasion and migration, which is a possible mechanism for the common early-stage manifestations of OCCC [51]. Overexpression of HNF1 $\beta$ in OCCC promotes glucose uptake and glycolysis, dramatically changing cellular metabolism to enhance oxidative stress resistance and benefiting cell survival [184]. Thus, glucose metabolism could be the therapeutic target of HNF1 $\beta$. Overexpression of HNF-1 $\beta$ is also shown to reduce ROS and protect cancer cells from the internal oxidative stress caused by the drastic changes in their cellular metabolism. It is proposed that HNF- $1 \beta$ may be pivotal for cancer cell survival due to antistress effects, rather than increased proliferative potential [185]. Furthermore, HNF1 $\beta$ is considered one of the factors contributing to resistance in OCCC, and knockdown of HNF1 $\beta$ can significantly improve cisplatin and paclitaxel sensitivity $[186,187]$. HNF1 $\beta$ inhibitors, microRNA mir-802 [187], may play a therapeutic role by destroying oxidative stress resistance (Figure 3) [5]. In addition, metformin has also been shown to depress cancer growth and promote paclitaxel sensitivity in mice [188]. HNF1 $\beta$ is a vital potential therapeutic target for OCCC whereas effective HNF1 $\beta$ inhibitors have not been found, and it has been commonly used as IHC biomarker.

\section{Immune Checkpoint Inhibitors}

It is currently believed that the immune microenvironment plays an important role in development and pathogenesis of tumors. The ability to evade immunity makes the immune microenvironment an emerging characteristic of cancer, and immune checkpoint blockade therapy has become more popular worldwide [29]. Up-regulation of several inflammatory cytokines and immune-related gene, as well as IL-6, STAT3 related genes is suggestive of an immune-suppressive microenvironment which may be associated with sensitivity to immune checkpoint inhibitors in OCCC. It has been indicated that effector memory CD8+ T cell phenotype, cytotoxic $\mathrm{T}$ lymphocyte-associated antigen-4 (CTLA-4), programmed death 1 (PD-1), T cell immunoglobulin and mucindomain containing-3 (Tim-3), and lymphocyte-activation gene-3 (LAG3) genes were overexpressed in OCCC, whereas 
expression of human leukocyte antigens (HLA) -A, -B, and $-C$ were decreased. These changes result in an immune-suppressive microenvironment which may serve as a promising therapeutic target in OCCC [185]. Several clinical trials of PD-1 and programmed death ligand 1 (PD-L1) monoclonal antibodies are outlined in Table 3 and Figure 3 [189-193]. In the 4 completed trails, avelumab, durvalumab+cediranib, pembrolizumab, and nivolumab have demonstrated significant efficacy and revealed the potential therapeutic efficacy as immune checkpoint inhibitors. Although these clinical trials had small OCCC sample sizes and needs further verification, anti-PD-1 or -PD-L1 antibody is a promising novel therapeutic drug for OCCC patients. A previous analysis found PD-L1 expression defects and mismatch repair (MMR) defects occurred in $43 \%$ and $67 \%$ of OCCC cases, respectively [194]. MMR deficiency is considered to be a predictive marker for immunotherapy such as anti-PD-1 and -PD-L1 antibodies, with a high sensitivity $[195,196]$. Glypican-3 (GPC3), a member of the glypican family of heparan sulfate proteoglycansone, is a potentially useful carcinoembryonic antigen for cancer vaccine immunotherapy and is overexpressed in OCCC [185]. In two small studies, OCCC patients were treated with a GPC3derived peptide vaccine, and the overall response rate was reported as 9.4\% (2 PR and 1 stable disease) [82] with the disease control rate of $17.9 \%$ in 32 patients [197]. Microsatellite instability (MSI) high tumors are associated with an enriched tumor mutation burden and a highly immunogenic phenotype. Women with Lynch syndrome, and a germline mutation of the mismatch repair genes (i.e., MLH1, MSH2, MSH6, and PMS2), have an increased life-time risk of colorectal, endometrial and ovarian cancer, including OCCC as well as endometrial ovarian carcinoma. Thus, Lynch syndrome should also be taken into consideration for the OCCC patients, especially with a Lynch syndrome related family history [185]. Therefore, the efficacy of immunotherapy in patients with OCCC should be further investigated in future clinical trials.

\section{Other potential therapeutic targets}

In addition to the targeted therapies described above, there are several promising therapeutic targets confirmed in clinic trials and preclinical studies. Lurbinectedin, a new agent that targets active transcription, exhibits antitumor activity in OCCC when used as a single agent and has synergistic antitumor effects when combined with irinotecan both as a first-line treatment and as a salvage treatment for recurrent lesions that develop after platinum-based or paclitaxel treatment [198]. The Japanese Gynecologic Oncology Group conducted the first randomized phase III, OCCC-specific clinical trial that compared irinotecan and cisplatin (CPT-P) with paclitaxel plus carboplatin (TC) in patients with OCCC, but no significant survival benefit was found for CPT-P [199]. Ferroptosis is associated with various pathological conditions, including acute kidney injury, hepatocellular degeneration and hemochromatosis, traumatic brain injury, and neurodegeneration. OCCC had an intrinsic vulnerability to glutathione peroxidase 4 (GPX4) inhibition-induced ferroptosis through the hypoxia-inducible factor (HIF) pathway, thus GPX4 was suggested as a therapeutic target in OCCC [200]. However, due to the poor bioavailability of current small-molecule GPX4 inhibitors, the efficacy of chemical inhibition of GPX4 remains to be demonstrated. ADP-ribosylation factor-like protein 4C (ARL4C) is also a potential therapeutic target in OCCC, which contributed to infiltration, metastasis, and chemotherapeutic resistance in OCCC via molecular mechanisms such as epithelial-tomesenchymal transition (EMT). Statins and bisphosphonates have a potential in ARL4C-targeted therapy in OCCC, but further studies are needed to verify its applicability [201]. EGLN (Egg-laying defective nine homolog) is a direct downstream sensor of oxygen tension. In OCCC, knockout or pharmacological inhibition of EGLN1 could stabilize HIF1A and inhibit proliferation in vitro and in vivo, suggesting that EGLN1 inhibition is a potential therapeutic strategy in OCCC [202].

There are still some potential targets need to be further explored, such as Fatty acid synthase (FASN), a potential downstream target of NAC1 in OCCC, and OCCC with FASN overexpression were more sensitive to a potent FASN inhibitor [203].By inhibition of anti-apoptotic protein MCL1 and BCL-XL/BCL-2, co-treatment with PF271and ABT737 was profoundly effective in inducing apoptosis of OCCC cell lines [204]. Suppression of ANXA4, which involved in proliferation, chemoresistance, and migration and invasion of OCCC, might be a potential target therapy of OCCC [205] Deregulation of Rho GTPases was common among OCCC, participating in tumorigenesis, invasiveness and metastasis. Several inhibitors targeting effectors and activators of the Rho GTPases are available, and their potential role in OCCC remains to be explored [206] LEFTY overexpression has anti-tumor effects in cellular proliferation and apoptosis which could helpful for therapy of OCCC [101]. In OCCC, miR-9 overexpression may affect pathogenesis by targeting E-cadherin, thereby inducing an epithelialmesenchymal transition. Therefore, miR-9 may be also a promising therapeutic target strategy [207]. 


\section{Prognosis \\ Primary OCCC}

The prognosis of early-stage OCCC is obviously superior to advanced OCCC. The 3-year survival rates for OCCC at stage I, II, III and IV are $80 \%, 47 \%, 34 \%$, and $30 \%$ for PFS, and $96 \%, 85 \%, 54 \%$, and $40 \%$ for OS, respectively [6, 7]. Among patients at early-stage, survival is better in OCCC compared to HGSC, but advanced-stage OCCC has worse outcomes compared with HGSC [208]. Intraoperative tumor rupture could lead to an iatrogenic stage increase of tumors from IA or IB to IC1, but the overflow of tumor cells during surgery does not seem to have an adverse impact on survival outcomes in stage I OCCC. Survival outcomes for stage IC1 OCCC have been reported to be similar to that of IA and IB, and are better than IC2 and IC3 [208]. The high rupture rate may be due to the related pelvic endometriosis, which leads to the formation of benign adhesions, making it hard to dissect tumors [106, 208]. However, in primary oophorectomy, it is still necessary to avoid tumor rupture [209].

In addition to FIGO stage, resistance to chemotherapy is also an independent prognostic factor in OCCC. For platinum-based chemotherapy, the overall response rate in OCCC is significantly lower than other types of EOC. Thus, compared with patients receiving non-platinum chemotherapy, platinum-based chemotherapy does not seem to improve the survival of OCCC patients [10, 92].

The extent of cytoreduction is another major factor in determining the prognosis of OCCC patients [210]. Optimal debulking is regarded to be very important, and significantly poorer prognosis has been observed, even in patients with small-volume disease [120]. Recurrent OCCC has much poorer survival [211].

Retroperitoneal lymph node metastasis is an effective indicator for decreased OS [72], and the lymph node ratio (LNR), which is the ratio of the number of metastatic lymph nodes (MLNs) to the number of resected lymph nodes (RLNs), is considered an independent prognostic predictor. Nie et al. verified that patients with advanced OCCC and an elevated LNR (>25\%) have unfavorable prognosis [212].

Patients with pathologically confirmed endometriosis-associated OCCC are 4 to 8 years younger at diagnosis than those without endometriosis [53, 213, 214], and they are more likely to diagnosed at early-stage manifestations and have higher probability of optimal debulking, lower CA-125 levels, and a higher rate of platinum-sensitivity [19, 45, 46, 48]. Patients with endometriosis-associated OCCC also tend to have lower percentages of LNM ( $15 \%$ to $17 \%$ vs $40 \%$ to $41 \%)$ and lymphovascular space invasion (LVSI) (23\% vs $51 \%$ ) compared with those without endometriosis-associated OCCC [46, 72]. The rate of 5 -year OS in patients with endometriosis is $70.2 \%$ to $74.1 \%$, compared with $46.4 \%$ to $52.6 \%$ for those without endometriosis, but most studies have concluded that the presence of endometriosis is not an independent prognosis factor after adjusting related clinical factors $[46,53,72,215]$.

VTE also adversely impacts patient survival, even after adjusting FIGO stage, with a shorter median OS (19 to 54 vs 90 to 140 months) and PFS (11 to 17 vs 43 to 76 months) compared with the cases without VTE, and its risk of recurrence and death increased by $3.9 \sim 6.3$ times $[77,90]$. The occurrence of VTE during primary therapy is also an independent predictor for prognosis [90]. Thus, it has been recommended that patients with OCCC may benefit from long-term anticoagulation. In addition, older age, positive peritoneal cytology, ascites, and omental involvement have also been found to be independent prognostic factors of OCCC $[72,216]$.

In addition, there are some other promising prognosis predictors. Recently, ten novel histotype-specific prognostic biomarkers for OCCC were reported, positive ARPC2, GNB1, KCTD10, NUP155, RPL13A, SETD3, SMYD2, and TRIO were related to poorer outcomes, whereas positive CCT5 and RPL37 were related to better prognosis [217]. In addition, high gene expression for CCNB2, CORO2A, CSNK1G1, FRMD8, LIN54, LINC00664, PDK1, and PEX6, were associated with shorter PFS for OCCC and endometrial ovarian carcinoma patients [218]. The high frequencies of neoantigens per somatic mutation (neoAg frequencies), rather than overall mutational load or number of predicted neoantigens per se, is an independent prognostic factor for decreased clinical outcome and low expression of immunity-associated genes [219]. Up-regulated rs4873815-TT/ZNF707, ARL4C, mitochondrial superoxide dismutase (SOD2) expression are predictive biomarkers for worse prognosis in OCCC [201, 220, 221]. And NAC1/FASN expression is a biomarker of poor outcome for patients treated with conventional platinum-based chemotherapy in OCCC by modulates sensitivity of ovarian cancer cells to cisplatin [203].

\section{Recurrent OCCC}

Recurrence rates have been reported to be $29 \%$, $30 \%, 62 \%$, and $73 \%$ for patients with OCCC at stages I, II, III and IV, respectively [15, 104]. Patients with recrudescent OCCC have an extremely poor 
prognosis, with a 5-year survival rate of merely $13.2 \%$ and a post-recurrence survival of 10.0 months, significantly lower than those with recurrent serous carcinoma (18.2\% and 18.9 months) [104, 105]. This is caused by the lower chemotherapy response rate and the absence of valid therapy for recurrent disease. After first-line chemotherapy, only $1 \%$ to $10 \%$ relapsed platinum-resistant OCCC patients could response to various second-line chemotherapy regimens [10, 33]. Despite adopting novel chemotherapy regimen and the investigation of novel combinations, there has been little improvement during the past few decades [105]. In Crotzer's research, of the 22 OCCC patients with platinumsensitivity, 2 patients $(9 \%)$ showed partial response to treatment with paclitaxel plus carboplatin, while in 83 OCCC patients with platinum-resistance, only 1 patient $(1 \%)$ showed partial response [222]. On the contrary, Takano et al. showed that even in the platinum-sensitive setting, response to chemotherapy was observed in only $8 \%$ (2 of 24) of patients [211]. Currently, there is no evidence to support whether chemotherapy plus cytoreduction is better than salvage chemotherapy alone for recurrent OCCC [105].

\section{Surveillance of High-Risk Groups}

In terms of surveillance, patients with a higher risk of OCCC should be closely monitored, including those with a long-term endometriosis, early menarche, late menopause, and a history of infertility associated with endometriosis, infertility treatment and ovarian endometrioma [223]. Owing to the poor prognosis of OCCC, asymptomatic patients should also pay attention to the regular gynecologic surveillance. Surgery should be considered if the tumor grows in regular follow-up $[6,10,11]$. The median time between diagnosis of endometriosis and diagnosis of OCCC is 50 months (ranging from 12 to 213 months). In consideration of the timing of cancer diagnosis and the duration of malignant transformation, Son et al. recommended that active surveillance to be considered beginning at age 35 years in patients with endometriosis, with examinations conducted at least once a year [215].

\section{Conclusion}

OCCC is a special pathological subtype of EOC that has its origin in endometriosis. The prognosis for advanced-stage OCCC is extremely poor because it has inherent platinum-resistance, so it is urgent to investigate more effective therapies. In this review, we summarized the pathogenesis, clinical features, molecular classification, diagnostic methods, future potential targeted treatments and prognosis biomarkers for OCCC. On the basis of the unique molecular characteristics of OCCC, several molecular-targeting drugs and immunotherapies have been extensively investigated in combination with conventional chemotherapy regimens. Although many combination therapy trials are currently underway or have been completed, precision therapy such as the PARP inhibitors and PD-1/PD-L1 antibodies may play an important role in OCCC treatment because it has been shown to be effective in HGSC and other cancers. However, personalized therapy based on the differences in genetic and molecular characteristics should also be pursued. Recent advances in molecular analysis of the clinical features of OCCC might contribute to future advances in the diagnosis and treatment of OCCC.

\section{Acknowledgements}

This work was supported by the National Natural Science Foundation of China (81872110, 81902632), National Key Research and Development Program (2018YFC1003900), the Strategic Priority Research Program of the Chinese Academy of Sciences (XDB29030000), the Ministry of Science and Technology of China (Grant 2016YFC1303503), Anhui Provincial Key Research and Development Program (1704a0802151). The funders had no role in the study design, data collection and analysis, decision to publish, or preparation of the manuscript.

\section{Competing Interests}

The authors have declared that no competing interest exists.

\section{References}

1. Siegel RL, Miller KD, Jemal A. Cancer statistics, 2019. CA Cancer J Clin. 2019; 69: 7-34.

2. Reid BM, Permuth JB, Sellers TA. Epidemiology of ovarian cancer: a review. Cancer Biol Med. 2017; 14: 9-32.

3. Chen W, Zheng R, Baade PD, Zhang S, Zeng H, Bray F, et al. Cancer statistics in China, 2015. CA: A Cancer Journal for Clinicians. 2016; 66: 115-32.

4. Itamochi H, Kigawa J, Terakawa N. Mechanisms of chemoresistance and poor prognosis in ovarian clear cell carcinoma. Cancer Sci. 2008; 99: 653-8.

5. Marks EI, Brown VS, Dizon DS. Genomic and Molecular Abnormalities in Gynecologic Clear Cell Carcinoma. Am J Clin Oncol. 2020; 43: 139-45.

6. Tang H, Liu Y, Wang X, Guan L, Chen W, Jiang H, et al. Clear cell carcinoma of the ovary: Clinicopathologic features and outcomes in a Chinese cohort. Medicine (Baltimore). 2018; 97: e10881.

7. Lee HY, Hong JH, Byun JH, Kim HJ, Baek SK, Kim JY, et al. Clinical Characteristics of Clear Cell Ovarian Cancer: A Retrospective Multicenter Experience of 308 Patients in South Korea. Cancer Res Treat. 2020; 52: 277-83.

8. Lee Y-Y, Kim T-J, Kim M-J, Kim H-J, Song T, Kim MK, et al. Prognosis of ovarian clear cell carcinoma compared to other histological subtypes: A meta-analysis. Gynecologic Oncology. 2011; 122: 541-7.

9. Yoshida K, Yoshikawa N, Shirakawa A, Niimi K, Suzuki S, Kajiyama H, et al. Prognostic value of neutrophil-to-lymphocyte ratio in early-stage ovarian clear-cell carcinoma. J Gynecol Oncol. 2019; 30: e85.

10. Takano M, Tsuda H, Sugiyama T. Clear cell carcinoma of the ovary: is there a role of histology-specific treatment? J Exp Clin Cancer Res. 2012; 31: 53.

11. Shu CA, Zhou Q, Jotwani AR, Iasonos A, Leitao MM, Jr., Konner JA, et al. Ovarian clear cell carcinoma, outcomes by stage: the MSK experience. Gynecol Oncol. 2015; 139: 236-41.

12. Prat J. Ovarian carcinomas: five distinct diseases with different origins, genetic alterations, and clinicopathological features. Virchows Arch. 2012; 460: 237-49.

13. Oliver KE, Brady WE, Birrer M, Gershenson DM, Fleming G, Copeland LJ, et al. An evaluation of progression free survival and overall survival of ovarian 
cancer patients with clear cell carcinoma versus serous carcinoma treated with platinum therapy: An NRG Oncology/Gynecologic Oncology Group experience. Gynecol Oncol. 2017; 147: 243-9.

14. Kim SI, Lim MC, Lim J, Won YJ, Seo SS, Kang S, et al. Incidence of epithelial ovarian cancer according to histologic subtypes in Korea, 1999 to 2012. J Gynecol Oncol. 2016; 27: e5.

15. Okamoto A, Glasspool RM, Mabuchi S, Matsumura N, Nomura H, Itamochi $\mathrm{H}$, et al. Gynecologic Cancer InterGroup (GCIG) consensus review for clear cell carcinoma of the ovary. Int J Gynecol Cancer. 2014; 24: S20-5.

16. Okamoto A, Sehouli J, Yanaihara N, Hirata Y, Braicu I, Kim BG, et al. Somatic copy number alterations associated with Japanese or endometriosis in ovarian clear cell adenocarcinoma. PLoS One. 2015; 10: e0116977.

17. Takahashi K, Takenaka M, Kawabata A, Yanaihara N, Okamoto A. Rethinking of treatment strategies and clinical management in ovarian clear cell carcinoma. Int J Clin Oncol. 2020; 25: 425-31.

18. Hiroko, Machida, Koji, Matsuo, Wataru, Yamagami, et al. Trends and characteristics of epithelial ovarian cancer in Japan between 2002 and 2015: A JSGO-JSOG joint study.

19. Ye S, Yang J, You Y, Cao D, Bai H, Lang J, et al. Comparative study of ovarian clear cell carcinoma with and without endometriosis in People's Republic of China. Fertil Steril. 2014; 102: 1656-62.

20. Carney JE, Terry KL, Goode BL, Wilkens LR, Ramus SJ, Jensen A, et al. Association between endometriosis and risk of histological subtypes of ovarian cancer: a pooled analysis of case-control studies. Lancet Oncology. 2012; 13: 385-94.

21. King CM, Barbara C, Prentice A, Brenton JD, Charnock-Jones DS. Models of endometriosis and their utility in studying progression to ovarian clear cell carcinoma. J Pathol. 2016; 238: 185-96.

22. Yamamoto A, Johnstone EB, Bloom MS, Huddleston HG, Fujimoto VY. A higher prevalence of endometriosis among Asian women does not contribute to poorer IVF outcomes. J Assist Reprod Genet. 2017; 34: 765-74.

23. Casagrande JT, Louie EW, Pike MC, Roy S, Ross RK, Henderson BE. "Incessant ovulation" and ovarian cancer. Lancet. 1979; 2: 170-3.

24. Huang Z, Gao Y, Wen W, Li H, Zheng W, Shu X-O, et al. Contraceptive methods and ovarian cancer risk among Chinese women: A report from the Shanghai Women\"s Health Study. International Journal of Cancer. 137: 607-14.

25. Wang C. Trends in contraceptive use and determinants of choice in China: 1980-2010. Contraception. 2012; 85: 570-9.

26. Ness RB, Dodge RC, Edwards RP, Baker JA, Moysich KB. Contraception methods, beyond oral contraceptives and tubal ligation, and risk of ovarian cancer. Ann Epidemiol. 2011; 21: 188-96.

27. Rice MS, Hankinson SE, Tworoger SS. Tubal ligation, hysterectomy, unilateral oophorectomy, and risk of ovarian cancer in the Nurses' Health Studies. Fertil Steril. 2014: 102: 192-8 e3.

28. Takayuki Enomoto DA, Kana Hattori, Masahisa Jinushi, Junzo Kigawa, Nobuhiro Takeshima, Hitoshi Tsuda, Yoh Watanabe, Kosuke Yoshihara, Toru Sugiyama. The first Japanese nationwide multicenter study of BRCA mutation testing in ovarian cancer: CHARacterizing the cross-sectionaLapproach to Ovarian cancer geneTic TEsting of BRCA (CHARLOTTE). Int J Gynecol Cancer. 2019; 29: 1043-9.

29. Khalique S, Lord CJ, Banerjee S, Natrajan R. Translational genomics of ovarian clear cell carcinoma. Semin Cancer Biol. 2020; 61: 121-31.

30. Tan DS, Miller RE, Kaye SB. New perspectives on molecular targeted therapy in ovarian clear cell carcinoma. Br J Cancer. 2013; 108: 1553-9.

31. Amano T, Chano T, Yoshino F, Kimura F, Murakami T. Current Position of the Molecular Therapeutic Targets for Ovarian Clear Cell Carcinoma: A Literature Review. Healthcare (Basel). 2019; 7.

32. Huang HN, Lin MC, Huang WC, Chiang YC, Kuo KT. Loss of ARID1A expression and its relationship with PI3K-Akt pathway alterations and ZNF217 amplification in ovarian clear cell carcinoma. Mod Pathol. 2014; 27: 983-90.

33. Mabuchi S, Sugiyama T, Kimura T. Clear cell carcinoma of the ovary: molecular insights and future therapeutic perspectives. J Gynecol Oncol. 2016; 27: e31.

34. Köbel M, Piskorz AM, Lee S, Lui S, Brenton JD. Optimized p53 immunohistochemistry is an accurate predictor of TP53 mutation in ovarian carcinoma: p53 immunohistochemistry predicts TP53 mutation status. Journal of Pathology Clinical Research. 2016; 2: 247-58.

35. Yang Q, Zhang C, Ren Y, Yi H, Luo T, Xing F, et al. Genomic characterization of Chinese ovarian clear cell carcinoma identifies driver genes by whole exome sequencing. Neoplasia. 2020; 22: 399-430.

36. Yamaguchi K, Huang Z, Matsumura N, Mandai M, Okamoto T, Baba T, et al. Epigenetic determinants of ovarian clear cell carcinoma biology. Int J Cancer. 2014; 135: 585-97.

37. Winterhoff B, Hamidi H, Wang C, Kalli KR, Fridley BL, Dering J, et al. Molecular classification of high grade endometrioid and clear cell ovarian cancer using TCGA gene expression signatures. Gynecol Oncol. 2016; 141: 95-100.

38. Parra-Herran C, Bassiouny D, Lerner-Ellis J, Olkhov-Mitsel E, Ismiil N, Hogen L, et al. p53, Mismatch Repair Protein, and POLE Abnormalities in Ovarian Clear Cell Carcinoma: An Outcome-based Clinicopathologic Analysis. Am J Surg Pathol. 2019; 43: 1591-9.
39. Choi JY, Han HH, Kim YT, Lee JH, Kim BG, Kang S, et al Ovarian Clear Cell Carcinoma Sub-Typing by ARID1A Expression. Yonsei Medical Journal. 2017; 58: 59 .

40. Hisham Abou-Taleb KY, Noriomi Matsumura, Ryusuke Murakami, Hidekatsu Nakai, Koichiro Higasa, Yasuaki Amano, Kaoru Abiko, Yumiko Yoshioka, Junzo Hamanishi, Masafumi Koshiyama, Tsukasa Baba, Ryo Yamada, Fumihiko Matsuda, Ikuo Konishi, Masaki Mandai. Comprehensive assessment of the expression of the SWI/SNF complex defines two distinct prognostic subtypes of ovarian clear cell carcinoma. Oncotarget. 2016; 7: 54758-70.

41. Tan TZ, Ye J, Yee CV, Lim D, Ngoi NYL, Tan DSP, et al. Analysis of gene expression signatures identifies prognostic and functionally distinct ovarian clear cell carcinoma subtypes. EBioMedicine. 2019; 50: 203-10.

42. Yuriko Uehara KO, Yuji Ikeda, Takahiro Koso, Shingo Tsuji, Shogo Yamamoto, Kayo Asada, Kenbun Sone, Reiko Kurikawa, Chinami Makii, Otoe Hagiwara, Michihiro Tanikawa, Daichi Maeda, Kosei Hasegawa, Shunsuke Nakagawa, Osamu Wada-Hiraike, Kei Kawana, Masashi Fukayama, Keiichi Fujiwara, Tetsu Yano, Yutaka Osuga, Tomoyuki Fujii, Hiroyuki Aburatani. Integrated Copy Number and Expression Analysis Identifies Profiles of Whole-Arm Chromosomal Alterations and Subgroups with Favorable Outcome in Ovarian Clear Cell Carcinomas. PLoS One. 2015; 10: e0128066.

43. Viganò $P$, Parazzini F, Somigliana E, Vercellini P. Endometriosis: epidemiology and aetiological factors. 2004; 18: 177-200.

44. Gupta D, Hull ML, Fraser I, Miller L, Bossuyt PMM, Johnson N, et al. Endometrial biomarkers for the non-invasive diagnosis of endometriosis. 2016.

45. Ishibashi $\mathrm{H}$, Takano $\mathrm{M}$, Miyamoto $\mathrm{M}$, Soyama $\mathrm{H}$, Matsuura $\mathrm{H}$, Aoyama $\mathrm{T}$, et al. Role of endometriosis as a prognostic factor for post-progression survival in ovarian clear cell carcinoma. Mol Clin Oncol. 2017; 7: 1027-31.

46. Paik ES, Kim TJ, Choi CH, Kim BG, Bae DS, Lee JW. Clinical outcomes of patients with clear cell and endometrioid ovarian cancer arising from endometriosis. J Gynecol Oncol. 2018; 29: e18.

47. Samartzis EP, Noske A, Dedes KJ, Fink D, Imesch P. ARID1A Mutations and PI3K/AKT Pathway Alterations in Endometriosis and EndometriosisAssociated Ovarian Carcinomas. International Journal of Molecular Sciences. 2013; 14: 18824-49.

48. Scarfone G, Bergamini A, Noli S, Villa A, Cipriani S, Taccagni G, et al. Characteristics of clear cell ovarian cancer arising from endometriosis: a two center cohort study. Gynecol Oncol. 2014; 133: 480-4.

49. Klemmt PAB, Starzinski-Powitz A. Molecular and Cellular Pathogenesis of Endometriosis. Current Women s Health Reviews. 2018; 14: 106-16.

50. Chandler RL, Damrauer JS, Raab JR, Schisler JC, Wilkerson MD, Didion JP, et al. Coexistent ARID1A-PIK3CA mutations promote ovarian clear-cell tumorigenesis through pro-tumorigenic inflammatory cytokine signalling. Nat Commun. 2015; 6: 6118.

51. Gounaris I, Brenton JD. Molecular pathogenesis of ovarian clear cell carcinoma. Future Oncol. 2015; 11: 1389-405.

52. Li X, Zhang Y, Zhao L, Wang L, Wu Z, Mei Q, et al. Whole-exome sequencing of endometriosis identifies frequent alterations in genes involved in cell adhesion and chromatin-remodeling complexes. Hum Mol Genet. 2014; 23: 6008-21.

53. Son JH, Yoon S, Kim S, Kong TW, Paek J, Chang SJ, et al. Clinicopathologic characteristics of ovarian clear cell carcinoma in the background of endometrioma: a surveillance strategy for an early detection of malignant transformation in patients with asymptomatic endometrioma. Obstet Gynecol Sci. 2019; 62: 27-34.

54. Kobayashi H, Sumimoto K, Moniwa N, Imai M, Takakura K, Kuromaki T, et al. Risk of developing ovarian cancer among women with ovarian endometrioma: a cohort study in Shizuoka, Japan. Int J Gynecol Cancer. 2007; 17: 37-43.

55. Anglesio MS, Papadopoulos N, Ayhan A, Nazeran TM, Noe M, Horlings HM, et al. Cancer-Associated Mutations in Endometriosis without Cancer. N Engl J Med. 2017; 376: 1835-48.

56. Hsu YH, Wang PH, Chang AC. Functional Gene Clusters in Global Pathogenesis of Clear Cell Carcinoma of the Ovary Discovered by Integrated Analysis of Transcriptomes. Int J Environ Res Public Health. 2020; 17.

57. Su KM, Lin TW, Liu LC, Yang YP, Wang ML, Tsai PH, et al. The Potential Role of Complement System in the Progression of Ovarian Clear Cell Carcinoma Inferred from the Gene Ontology-Based Immunofunctionome Analysis. Int J Mol Sci. 2020; 21.

58. Oseledchyk A, Leitao MM, Jr., Konner J, O'Cearbhaill RE, Zamarin D, Sonoda $\mathrm{Y}$, et al. Adjuvant chemotherapy in patients with stage I endometrioid or clear cell ovarian cancer in the platinum era: a Surveillance, Epidemiology, and End Results Cohort Study, 2000-2013. Ann Oncol. 2017; 28: 2985-93.

59. Mangili G, Bergamini A, Taccagni G, Gentile C, Panina P, Viganò P, et al. Unraveling the two entities of endometrioid ovarian cancer: A single center clinical experience. Gynecologic Oncology. 126: 403---7.

60. Yamamoto A, Johnstone EB, Bloom MS, Huddleston HG, Fujimoto VY. A higher prevalence of endometriosis among Asian women does not contribute to poorer IVF outcomes. J Assist Reprod Genet 2017; 34: 765-74.

61. Wang S, Qiu L, Lang JH, Shen K, Yang JX, Huang HF, et al. Clinical analysis of ovarian epithelial carcinoma with coexisting pelvic endometriosis. Am J Obstet Gynecol. 2013; 208: 413 e1-5. 
62. Tothill RW, Tinker AV, Grorge J, et al. Novel Molecular Subtypes of Serous and Endometrioid Ovarian Cancer Linked to Clinical Outcome. Clinical Cancer Research. 2008; 14: 5198-208.

63. Integrated genomic analysis of ovarian carcinoma. Science-Business eXchange. 2011; 4(782).

64. Bennett JA, Dong F, Young RH, Oliva E. Clear cell carcinoma of the ovary: evaluation of prognostic parameters based on a clinicopathological analysis of 100 cases. Histopathology. 2015; 66: 808-15.

65. Zhang $\mathrm{H}$, Lerwill $\mathrm{M}$. Co-existence of three rare gynecological tumors in a 79-year-old woman. Arch Gynecol Obstet. 2011; 284: 695-8.

66. Kajihara H, Yamada Y, Shigetomi H, Higashiura Y, Kobayashi H. The dichotomy in the histogenesis of endometriosis-associated ovarian cancer: clear cell-type versus endometrioid-type adenocarcinoma. Int J Gynecol Pathol. 2012; 31: 304.

67. Cochrane DR, Tessier-Cloutier B, Lawrence KM, Nazeran T, Karnezis AN, Salamanca C, et al. Clear cell and endometrioid carcinomas: are their differences attributable to distinct cells of origin? J Pathol. 2017; 243: 26-36.

68. Komiyama S, Nagashima M, Taniguchi T, Yokouchi Y, Kugimiya T. Ovarian Clear Cell Carcinoma Detected During Long-Term Management of Endometriotic Cysts in Young Patients: Possible Heterogeneity of this Tumor. Gynecol Obstet Invest. 2019; 84: 305-12.

69. Davis M, Rauh-Hain JA, Andrade C, Boruta DM, Schorge JO, Horowitz NS, et al. Comparison of clinical outcomes of patients with clear cell and endometrioid ovarian cancer associated with endometriosis to papillary serous carcinoma of the ovary. Gynecologic Oncology. 2014; 132: 760-6.

70. Zhao C, Wu LS, Barner R. Pathogenesis of ovarian clear cell adenofibroma, atypical proliferative (borderline) tumor, and carcinoma: clinicopathologic features of tumors with endometriosis or adenofibromatous components support two related pathways of tumor development. J Cancer. 2011; 2: 94-106.

71. Anglesio MS, George J, Kulbe H, Friedlander M, Rischin D, Lemech C, et al. IL6-STAT3-HIF signaling and therapeutic response to the angiogenesis inhibitor sunitinib in ovarian clear cell cancer. Clin Cancer Res. 2011; 17: 2538-48

72. Sahin H, Sari ME, Cuylan ZF, Haberal AN, Sirvan L, Coban G, et al. Is the presence of endometriosis associated with a survival benefit in pure ovarian clear cell carcinoma? Arch Gynecol Obstet. 2018; 297: 1005-13.

73. Pozzati F, Moro F, Pasciuto T, Gallo C, Ciccarone F, Franchi D, et al. Imaging in gynecological disease (14): clinical and ultrasound characteristics of ovarian clear cell carcinoma. Ultrasound Obstet Gynecol. 2018; 52: 792-800.

74. Li X, Ye Z. Clear cell carcinoma of the ovary: multi-slice computed tomography findings. World J Surg Oncol. 2015; 13: 133.

75. Stukan M, Bugalho A, Kumar A, Kowalewska J, Swietlik D, Buda N, et al. Lung and Intercostal Upper Abdomen Ultrasonography for Staging Patients with Ovarian Cancer: A Method Description and Feasibility Study. Diagnostics (Basel). 2020; 10.

76. Metcalf RL, Fry DJ, Swindell R, McGurk A, Clamp AR, Jayson GC, et al. Thrombosis in ovarian cancer: a case control study. Br J Cancer. 2014; 110: 1118-24.

77. Ye S, Yang J, Cao D, Bai H, Huang $\mathrm{H}, \mathrm{Wu} \mathrm{M}$, et al. Characteristic and prognostic implication of venous thromboembolism in ovarian clear cell carcinoma: a 12-year retrospective study. PLoS One. 2015; 10: e0121818.

78. Sakurai M, Matsumoto K, Gosho M, Sakata A, Hosokawa Y, Tenjimbayashi Y, et al. Expression of Tissue Factor in Epithelial Ovarian Carcinoma Is Involved in the Development of Venous Thromboembolism. International Journal of Gynecological Cancer. 2017.

79. Takasaki K, Miyamoto M, Takano M, Soyama H, Aoyama T, Matsuura H, et al. Thrombotic events induce the worse prognosis in ovarian carcinomas and frequently develop in ovarian clear cell carcinoma. Int J Clin Oncol. 2019; 24: 1273-83.

80. Swier N, Versteeg HH. Reciprocal links between venous thromboembolism, coagulation factors and ovarian cancer progression. Thrombosis Research. 2017; 150: 8-18.

81. Duska LR, Garrett L, Henretta M, Ferriss JS, Lee L, Horowitz N. When 'never-events' occur despite adherence to clinical guidelines: the case of venous thromboembolism in clear cell cancer of the ovary compared with other epithelial histologic subtypes. Gynecol Oncol. 2010; 116: 374-7.

82. Matsuura Y, Robertson G, Marsden DE, Kim SN, Gebski V, Hacker NF. Thromboembolic complications in patients with clear cell carcinoma of the ovary. Gynecol Oncol. 2007; 104: 406-10.

83. Zakai NA, Lutsey PL, Folsom AR, Heckbert SR, Cushman M. Total tissue factor pathway inhibitor and venous thrombosis. The Longitudinal Investigation of Thromboembolism Etiology. Thromb Haemost. 2010; 104: 207-12.

84. Cuff J, Salari K, Clarke N, Esheba GE, Forster AD, Huang S, et al. Integrative bioinformatics links HNF1B with clear cell carcinoma and tumor-associated thrombosis. PLoS One 2013; 8: e74562.

85. Satoh T, Oki A, Uno K, Sakurai M, Ochi H, Okada S, et al. High incidence of silent venous thromboembolism before treatment in ovarian cancer. 2007; 97: 1053-7.

86. Zhou Q, Zhu C, Shen Z, Zhang T, Li M, Zhu J, et al. Incidence and potential predictors of thromboembolic events in epithelial ovarian carcinoma patients during perioperative period. Eur J Surg Oncol. 2020.

87. Ebina Y, Uchiyama M, Imafuku H, Suzuki K, Miyahara Y, Yamada H. Risk factors for deep venous thrombosis in women with ovarian cancer. Medicine (Baltimore). 2018; 97: e11009.
88. Khorana AA, Kuderer NM, Culakova E, Lyman GH, Francis CW. Development and validation of a predictive model for chemotherapy-associated thrombosis. Blood. 2008; 111: 4902-7.

89. Cohen AT, Nandini B, Wills JO, Ota S. VTE prophylaxis for the medical patient: where do we stand? - A focus on cancer patients. Thrombosis Research. 2010; 125(Suppl 2):21-9.

90. Diaz ES, Walts AE, Karlan BY, Walsh CS. Venous thromboembolism during primary treatment of ovarian clear cell carcinoma is associated with decreased survival. Gynecologic Oncology. 2013; 131: 541-5.

91. Liu H, Xu Y, Ji J, Dong R, Qiu H, Dai X. Prognosis of ovarian clear cell cancer compared with other epithelial cancer types: A population-based analysis. Oncology Letters. 2020

92. Kobayashi H, Sugimoto H, Onishi S, Nakano K. Novel biomarker candidates for the diagnosis of ovarian clear cell carcinoma. Oncol Lett. 2015; 10: 612-8.

93. Kim HS, Choi HY, Lee M, Suh DH, Kim K, No JH, et al. Systemic Inflammatory Response Markers and CA-125 Levels in Ovarian Clear Cell Carcinoma: A Two Center Cohort Study. Cancer Res Treat. 2016; 48: 250-8.

94. Tian C, Markman M, Zaino R, Ozols RF, McGuire WP, Muggia FM, et al. CA-125 change after chemotherapy in prediction of treatment outcome among advanced mucinous and clear cell epithelial ovarian cancers: a Gynecologic Oncology Group study. Cancer. 2009; 115: 1395-403.

95. Grivennikov SI, Greten FR, Karin M. Immunity, inflammation, and cancer. Cell. 2010; 140: 883-99.

96. Kwon BS, Jeong DH, Byun JM, Lee TH, Choi KU, Song YJ, et al. Prognostic value of preoperative lymphocyte-monocyte ratio in patients with ovarian clear cell carcinoma. J Cancer. 2018; 9: 1127-34.

97. Lippi G, Meschi T, Nouvenne A, Mattiuzzi C, Borghi L. Neutrophil Gelatinase-Associated Lipocalin in Cancer. Advances in Clinical Chemistry. 2014; 64: 179-219.

98. Zhang H, Lu J, Lu Y, Zhou J, Xu C. Prognostic significance and predictors of the system inflammation score in ovarian clear cell carcinoma. Plos One. 2017; 12: $\mathrm{e} 0177520$.

99. Tsuchiya A, Sakamoto M, Yasuda J, Chuma M, Ohta T, Ohki M, et al. Expression profiling in ovarian clear cell carcinoma: identification of hepatocyte nuclear factor-1 beta as a molecular marker and a possible molecular target for therapy of ovarian clear cell carcinoma. Am J Pathol. 2003; 163: 2503-12

100. McCluggage WG. Morphological subtypes of ovarian carcinoma: a review with emphasis on new developments and pathogenesis. Pathology. 2011; 43: 420-32.

101. Masashi Akiya MY, Toshihide Matsumoto, Yusuke Kawashima, Yasuko Oguri, Sabine Kajita, Daiki Kijima, Risako Chiba, Ako Yokoi, Hiroyuki Takahashi, Yoshio Kodera and Makoto Saegusa. Identification of LEFTY as a molecular marker for ovarian clear cell carcinoma. Oncotarget. 2017; 8: 63646-64.

102. Vilming Elgaaen B, Olstad OK, Haug KB, Brusletto B, Sandvik L, Staff AC, et al. Global miRNA expression analysis of serous and clear cell ovarian carcinomas identifies differentially expressed miRNAs including miR-200c-3p as a prognostic marker. BMC Cancer. 2014; 14: 80.

103. Zhang X, Guo G, Wang G, Zhao J, Wang B, Yu X, et al. Profile of differentially expressed miRNAs in high-grade serous carcinoma and clear cell ovarian carcinoma, and the expression of miR-510 in ovarian carcinoma. Mol Med Rep. 2015; 12: 8021-31.

104. Kajiyama H, Shibata K, Mizuno M, Yamamoto E, Fujiwara S, Umezu T, et al. Postrecurrent oncologic outcome of patients with ovarian clear cell carcinoma. Int J Gynecol Cancer. 2012; 22: 801-6.

105. Kajiyama H, Suzuki S, Yoshikawa N, Kawai M, Shibata K, Nagasaka T, et al. Oncologic outcomes after secondary surgery in recurrent clear-cell carcinoma of the ovary. Int J Gynecol Cancer. 2019; 29: 910-5.

106. Padhy RR, Savage J, Kurman RJ. Comprehensive Surgical Staging in Stage 1 Clear Cell and Endometrioid Ovarian Carcinomas: Is it Necessary? International Journal of Gynecological Pathology. 2019.

107. Szubert M, Suzin J, Obirek K, Sochacka A, Loszakiewicz M. Clear cell ovarian cancer and endometriosis: is there a relationship? Prz Menopauzalny. 2016; 15 : 85-9.

108. Mueller JJ, Holzapfel M, Han CH, Santos K, Gunderson C, Moore K, et al. Staging Lymphadenectomy in Patients With Clear Cell Carcinoma of the Ovary. Int J Gynecol Cancer. 2016; 26: 120-4.

109. Ye S, Zhou S, Chen W, Xiang L, Wu X, Yang H. Recurrence Patterns and Survival Outcomes in Chinese Patients with Surgically Treated Recurrent Ovarian Clear Cell Carcinoma: A Single Institutional Analysis of 45 Cases. Cancer Manag Res. 2020; 12: 913-9.

110. Lv M, Li Y, Luo C, Liu P, Yang J. Splenic metastasis of ovarian clear cell adenocarcinoma: A case report and review of the literature. Exp Ther Med. 2014; 7: 982-6.

111. Akashi D, Todo Y, Okamoto K, Minobe S, Kato H. Achievement of 10-year survival: a case of pubic bone recurrence as the primary failure site of chemo-refractory ovarian clear cell carcinoma. J Obstet Gynaecol Res. 2013; 39: 1359-62.

112. Jenison EL, Montag AG, Griffiths CT, Welch WR, Lavin PT, Greer J, et al. Clear cell adenocarcinoma of the ovary: a clinical analysis and comparison with serous carcinoma. Gynecol Oncol. 1989; 32: 65-71.

113. Pectasides D, Fountzilas G, Aravantinos G, Kalofonos C, Efstathiou $H_{\text {, }}$ Farmakis D, et al. Advanced stage clear-cell epithelial ovarian cancer: the 
Hellenic Cooperative Oncology Group experience. Gynecol Oncol. 2006; 102: 285-91.

114. Kumar A, Gilks CB, Mar C, Santos J, Tinker AV. Patterns of spread of clear cell ovarian cancer: Case report and case series. Gynecol Oncol Case Rep. 2013; 6: 25-7.

115. Pakneshan S, Safarpour D, Tavassoli F, Jabbari B. Brain metastasis from ovarian cancer: a systematic review. J Neurooncol. 2014; 119: 1-6.

116. Marchetti C, Ferrandina G, Cormio G, Gambino A, Cecere S, Lorusso D, et al. Brain metastases in patients with EOC: Clinico-pathological and prognostic factors. A multicentric retrospective analysis from the MITO group (MITO 19). Gynecol Oncol. 2016; 143: 532-8.

117. Nafisi H, Cesari M, Karamchandani J, Balasubramaniam G, Keith JL. Metastatic ovarian carcinoma to the brain: an approach to identification and classification for neuropathologists. Neuropathology. 2015; 35: 122-9.

118. Takami M, Kita E, Kuwana Y, Ohta Y, Nakayama Y, Fukai H, et al. [A case of brain metastasis from advanced ovarian clear-cell carcinoma during maintenance chemotherapy with irinotecan+cisplatin]. Gan To Kagaku Ryoho. 2008; 35: 1243-5.

119. Liu P, Liu W, Feng Y, Xiao X, Zhong M. Brain metastasis from ovarian clear cell carcinoma: A case report. Medicine (Baltimore). 2019; 98: e14020.

120. Chan JK, Tian C, Fleming GF, Monk BJ, Herzog TJ, Kapp DS, et al. The potential benefit of 6 vs. 3 cycles of chemotherapy in subsets of women with early-stage high-risk epithelial ovarian cancer: an exploratory analysis of a Gynecologic Oncology Group study. Gynecol Oncol. 2010; 116: 301-6.

121. Vergote I, Trope CG, Amant F, Kristensen GB, Ehlen T, Johnson N, et al. Neoadjuvant chemotherapy or primary surgery in stage IIIC or IV ovarian cancer. N Engl J Med. 2010; 363: 943-53.

122. Kehoe S, Hook J, Nankivell M, et al. Primary chemotherapy versus primary surgery for newly diagnosed advanced ovarian cancer (CHORUS): an open-label, randomised, controlled, non-inferiority trial.Clinical Trial. 2015; 386(9990):249-57.

123. Yamazaki H, Todo Y, Shimada C, Takeshita S, Minobe S, Okamoto K, et al. Therapeutic significance of full lymphadenectomy in early-stage ovarian clear cell carcinoma. J Gynecol Oncol. 2018; 29: e19.

124. Takei $Y$, Takahashi S, Machida S, Taneichi A, Yoshiba T, Takahashi Y, et al. Impact of the number of removed lymph nodes on recurrence-free survival in stage I ovarian clear cell carcinoma. Int J Clin Oncol. 2018; 23: 930-5.

125. Magazzino F, Katsaros D, Ottaiano A, Gadducci A, Pignata S. Surgical and Medical Treatment of Clear Cell Ovarian Cancer Results From the Multicenter Italian Trials in Ovarian Cancer (MITO) 9 Retrospective Study. International Journal of Gynecological Cancer. 2011; 21: 1063-70.

126. Suzuki K, Takakura S, Saito M, Morikawa A, Suzuki J, Takahashi K, et al. Impact of Surgical Staging in Stage I Clear Cell Adenocarcinoma of the Ovary. International Journal of Gynecological Cancer Official Journal of the International Gynecological Cancer Society. 2014; 24: 1181-9.

127. Bommert M, Harter P, Heitz F, du Bois A. When should Surgery be used for Recurrent Ovarian Carcinoma? Clinical Oncology. S0936655518302358.

128. Petrillo M, Fagotti A, Ferrandina G, Fanfani F, Costantini B, Vizzielli G, et al. Ovarian cancer patients with localized relapse: clinical outcome and prognostic factors. Gynecol Oncol. 2013; 131: 36-41.

129. Yoshihara M, Kajiyama H, Tamauchi S, Suzuki S, Takahashi K, Matsui S, et al. Prognostic factors and effects of fertility-sparing surgery in women of reproductive age with ovarian clear-cell carcinoma: a propensity score analysis. J Gynecol Oncol. 2019; 30: e102.

130. Dimitrios N, Eloise C-D, K. FM, S. WS, Kevin H. Could fertility-sparing surgery be considered for women with early stage ovarian clear cell carcinoma? Journal of Gynecologic Oncology. 28: e71-.

131. Satoh T, Hatae M, Watanabe Y, Yaegashi N, Ishiko O, Kodama S, et al. Outcomes of fertility-sparing surgery for stage I epithelial ovarian cancer: a proposal for patient selection. J Clin Oncol. 2010; 28: 1727-32.

132. Kajiyama H, Suzuki S, Yoshikawa N, Niimi K, Kawai M, Shibata K, et al. Long-term oncologic outcome and its prognostic indicators in reproductive-age women with ovarian clear-cell carcinoma. Arch Gynecol Obstet. 2019; 300: 717-24

133. Schwartz DR, Kardia SL, Shedden KA, Kuick R, Michailidis G, Taylor JM, et al. Gene expression in ovarian cancer reflects both morphology and biological behavior, distinguishing clear cell from other poor-prognosis ovarian carcinomas. Cancer Research. 2002; 62: 4722

134. Reed E, Jing JY, Davies A, Gannon J, Armentrout SL. Clear Cell Tumors Have Higher mRNA Levels of ERCC1 and XPB Than Other Histological Types of Epithelial Ovarian Cancer. Clinical Cancer Research An Official Journal of the American Association for Cancer Research. 2003; 9: 5299.

135. Cai KQ, Albarracin C, Rosen D, Zhong R, Zheng W, Luthra R, et al. Microsatellite instability and alteration of the expression of hMLH1 and hMSH2 in ovarian clear cell carcinoma. Hum Pathol. 2004; 35: 552-9.

136. Itamochi H, Kigawa J, Sugiyama T, Kikuchi Y, Suzuki M, Terakawa N. Low proliferation activity may be associated with chemoresistance in clear cell carcinoma of the ovary. Obstetrics \& Gynecology. 100: 0-287.

137. Takada $T$, Iwase $H$, Iitsuka $C$, Nomura $H$, Sakamoto $K$, Omatsu $K$, et al. Adjuvant chemotherapy for stage I clear cell carcinoma of the ovary: an analysis of fully staged patients. Int J Gynecol Cancer. 2012; 22: 573-8.

138. Bogani G, Ditto A, Lopez S, Bertolina F, Murgia F, Pinelli C, et al. Adjuvant chemotherapy vs. observation in stage I clear cell ovarian carcinoma: A systematic review and meta-analysis. Gynecologic Oncology. 2020.
139. Lorusso D, Pignata S. Role of adjuvant chemotherapy in early-stage endometrioid and clear-cell ovarian cancer. Ann Oncol. 2017; 28: 2909-11.

140. Prendergast EN, Holzapfel M, Mueller JJ, Leitao MM, Jr., Gunderson CC, Moore $\mathrm{KN}$, et al. Three versus six cycles of adjuvant platinum-based chemotherapy in early stage clear cell ovarian carcinoma - A multi-institutional cohort. Gynecol Oncol. 2017; 144: 274-8.

141. Kuroda T, Ogiwara H, Sasaki M, Takahashi K, Yoshida H, Kiyokawa T, et al. Therapeutic preferability of gemcitabine for ARID1A-deficient ovarian clear cell carcinoma. Gynecol Oncol. 2019; 155: 489-98.

142. Kuroda T, Kohno T. Precision medicine for ovarian clear cell carcinoma based on gene alterations. International Journal of Clinical Oncology. 2020; 25: 419-24.

143. Yoshino K, Enomoto T, Fujita M, Ueda Y, Kimura T, Kobayashi E, et al. Salvage chemotherapy for recurrent or persistent clear cell carcinoma of the ovary: a single-institution experience for a series of 20 patients. Int J Clin Oncol. 2013; 18: 148-53.

144. Takano M, Kikuchi Y, Kudoh K, Goto T, Furuya K, Kikuchi R, et al. Weekly administration of temsirolimus for heavily pretreated patients with clear cell carcinoma of the ovary: a report of six cases. Int J Clin Oncol. 2011; 16: 605-9.

145. Alsop K, Fereday S, Meldrum C, deFazio A, Emmanuel C, George J, et al. BRCA mutation frequency and patterns of treatment response in BRCA mutation-positive women with ovarian cancer: a report from the Australian Ovarian Cancer Study Group. J Clin Oncol. 2012; 30: 2654-63.

146. Shen J, Peng Y, Wei L, Zhang W, Yang L, Lan L, et al. ARID1A Deficiency Impairs the DNA Damage Checkpoint and Sensitizes Cells to PARP Inhibitors. Cancer Discov. 2015; 5: 752-67.

147. Williamson CT, Miller R, Pemberton HN, Jones SE, Campbell J, Konde A, et al. ATR inhibitors as a synthetic lethal therapy for tumours deficient in ARID1A. Nature Communications. 7: 13837

148. Caumanns JJ, Wisman GBA, Berns K, van der Zee AGJ, de Jong S. ARID1A mutant ovarian clear cell carcinoma: A clear target for synthetic lethal strategies. Biochim Biophys Acta Rev Cancer. 2018; 1870: 176-84.

149. Kim KH, Kim W, Howard TP, Vazquez F, Tsherniak A, Wu JN, et al. SWI/SNF-mutant cancers depend on catalytic and non-catalytic activity of EZH2. Nat Med. 2015; 21: 1491-6.

150. Bitler BG, Aird KM, Garipov A, Li H, Amatangelo M, Kossenkov AV, et al. Synthetic lethality by targeting EZH2 methyltransferase activity in ARID1A-mutated cancers. Nat Med. 2015; 21: 231-8.

151. Kim KH, Roberts CW. Targeting EZH2 in cancer. Nat Med. 2016; 22: 128-34.

152. Fukumoto T, Park PH, Wu S, Fatkhutdinov N, Karakashev S, Nacarelli T, et al. Repurposing Pan-HDAC Inhibitors for ARID1A-Mutated Ovarian Cancer. Cell Rep. 2018; 22: 3393-400.

153. Bitler BG, Wu S, Park PH, Hai Y, Aird KM, Wang Y, et al. ARID1A-mutated ovarian cancers depend on HDAC6 activity. Nat Cell Biol. 2017; 19: 962-73.

154. Yee AJ, Bensinger WI, Supko JG, Voorhees PM, Berdeja JG, Richardson PG, et al. Ricolinostat plus lenalidomide, and dexamethasone in relapsed or refractory multiple myeloma: a multicentre phase $1 \mathrm{~b}$ trial. Lancet Oncol. 2016; 17: $1569-78$

155. Berns K, Caumanns J, Gennissen AMC, Evers B, Bernards R. ARID1A mutation sensitizes most ovarian clear cell carcinomas to BET inhibitors. Oncogene. 2018; 37.

156. Miller RE, Brough R, Bajrami I, Williamson CT, McDade S, Campbell J, et al. Synthetic Lethal Targeting of ARID1A-Mutant Ovarian Clear Cell Tumors with Dasatinib. Mol Cancer Ther. 2016; 15: 1472-84.

157. Guan B, Wang TL, Shih IM. ARID1A, a Factor That Promotes Formation of SWI/SNF- Mediated Chromatin Remodeling, Is a Tumor Suppressor in Gynecologic Cancers.

158. Gorrini C, Mak TW. Glutathione Metabolism: An Achilles' Heel of ARID1A-Deficient Tumors. Cancer Cell. 2019; 35: 161-3.

159. Ogiwara H, Takahashi K, Sasaki M, Kuroda T, Yoshida H, Watanabe R, et al. Targeting the Vulnerability of Glutathione Metabolism in ARID1A-Deficient Cancers. Cancer Cell. 2019; 35: 177-90 e8.

160. Engelman JA. Targeting PI3K signalling in cancer: opportunities, challenges and limitations. Nat Rev Cancer. 2009; 9: 550-62.

161. Itamochi H, Oishi T, Oumi N, Takeuchi S, Yoshihara K, Mikami M, et al. Whole-genome sequencing revealed novel prognostic biomarkers and promising targets for therapy of ovarian clear cell carcinoma. Br J Cancer. 2017; 117: 717-24.

162. Kim SI, Lee JW, Lee M, Kim HS, Chung HH, Kim JW, et al. Genomic landscape of ovarian clear cell carcinoma via whole exome sequencing. Gynecol Oncol. 2018; 148: 375-82.

163. Jin $Y$, Li Y, Pan $L$. The target therapy of ovarian clear cell carcinoma. Onco Targets Ther. 2014; 7: 1647-52

164. Mabuchi S, Kawase C, Altomare DA, Morishige K, Sawada K, Hayashi M, et al. mTOR Is a Promising Therapeutic Target Both in Cisplatin-Sensitive and Cisplatin-Resistant Clear Cell Carcinoma of the Ovary. Clinical Cancer Research. 15: 5404-13.

165. Tanaka H, Yoshida M, Tanimura H, Fujii T, Sakata K, Tachibana Y, et al. The selective class I PI3K inhibitor CH5132799 targets human cancers harboring oncogenic PIK3CA mutations. Clin Cancer Res. 2011; 17: 3272-81.

166. Yap TA, Yan L, Patnaik A, Fearen I, Olmos D, Papadopoulos K, et al. First-in-man clinical trial of the oral pan-AKT inhibitor MK-2206 in patients with advanced solid tumors. J Clin Oncol. 2011; 29: 4688-95. 
167. Sasano T, Mabuchi S, Kuroda H, Kawano M, Matsumoto Y, Takahashi R, et al. Preclinical Efficacy for AKT Targeting in Clear Cell Carcinoma of the Ovary. Molecular Cancer Research. 2015; 13: 795-806.

168. Hisamatsu T, Mabuchi S, Matsumoto Y, Kawano M, Sasano T, Takahashi R, et al. Potential role of mTORC2 as a therapeutic target in clear cell carcinoma of the ovary. Mol Cancer Ther. 2013; 12: 1367-77.

169. Nagaraja AK, Creighton CJ, Yu Z, Zhu H, Gunaratne PH, Reid JG, et al. A Link between mir-100 and FRAP1/mTOR in Clear Cell Ovarian Cancer. Molecular Endocrinology. 2010; 24: 447-63.

170. Farley JH BW, Fujiwara K, et al. A phase II evaluation of temsirolimus in combination with carboplatin and paclitaxel followed by temsirolimus consolidation as first-line therapy in the treatment of stage III-IV clear cell carcinoma of the ovary. J Clin Oncol. 34: 5531.

171. Yamamoto $\mathrm{S}$, Tsuda $\mathrm{H}$, Takano M, Tamai S, Matsubara O. Loss of ARID1A protein expression occurs as an early event in ovarian clear-cell carcinoma development and frequently coexists with PIK3CA mutations. Modern Pathology An Official Journal of the United States \& Canadian Academy of Pathology Inc. 25: 615-24.

172. Fujimura M, Katsumata N, Tsuda H, Uchi N, Miyazaki S, Hidaka T, et al. HER2 is frequently over-expressed in ovarian clear cell adenocarcinoma: possible novel treatment modality using recombinant monoclonal antibody against HER2, trastuzumab. Japanese journal of cancer research : Gann. 2002; 93: $1250-7$.

173. Bookman MA, Darcy KM, Clarke-Pearson D, Boothby RA, Horowitz IR Evaluation of monoclonal humanized anti-HER2 antibody, trastuzumab, in patients with recurrent or refractory ovarian or primary peritoneal carcinoma with overexpression of HER2: a phase II trial of the Gynecologic Oncology Group. J Clin Oncol. 2003; 21: 283-90.

174. Yodoi J, Yamashita Y, Akatsuka S, Shinjo K, Yatabe Y, Kobayashi H, et al. Met Is the Most Frequently Amplified Gene in Endometriosis-Associated Ovarian Clear Cell Adenocarcinoma and Correlates with Worsened Prognosis. PLoS ONE. 2013; 8: e57724.

175. Kim HJ, Yoon A, Ryu JY, Cho YJ, Choi JJ, Song SY, et al. c-MET as a Potential Therapeutic Target in Ovarian Clear Cell Carcinoma. Scientific Reports. 6: 38502.

176. Konstantinopoulos PA, Brady WE, Farley J. Phase II study of single-agent cabozantinib in patients with recurrent clear cell ovarian, primary peritoneal or fallopian tube cancer (NRG-GY001). 2018

177. Chan JK, William B, J. MB, Jubilee B, S. SM, G. RP, et al. A phase II evaluation of sunitinib in the treatment of persistent or recurrent clear cell ovarian carcinoma: An NRG Oncology/Gynecologic Oncology Group Study (GOG-254). Gynecologic Oncology. S0090825818309417-.

178. Mabuchi S, Kawase C, Altomare DA, Morishige K, Hayashi M, Sawada K, et al. Vascular endothelial growth factor is a promising therapeutic target for the treatment of clear cell carcinoma of the ovary. Mol Cancer Ther. 2010; 9: 2411-22.

179. Komiyama S, Kato K, Inokuchi $\mathrm{Y}$, Takano H, Matsumoto T, Hongo A, et al. Bevacizumab combined with platinum-taxane chemotherapy as first-line treatment for advanced ovarian cancer: a prospective observational study of safety and efficacy in Japanese patients (JGOG3022 trial). Int J Clin Oncol. 2019; $24: 103-14$

180. Lheureux S, Tinker A, Clarke B, Ghatage P, Welch S, Weberpals JI, et al. A Clinical and Molecular Phase II Trial of Oral ENMD-2076 in Ovarian Clear Cell Carcinoma (OCCC): A Study of the Princess Margaret Phase II Consortium. Clin Cancer Res. 2018; 24: 6168-74

181. Glasspool RM, McNeish IA, Paul J, Lawless CA, Mirza MR. NiCCC (ENGOT-GYN1): A randomized phase II study of nintedanib (BIBF1120) compared to chemotherapy in patients with recurrent clear-cell carcinoma of the ovary or endometrium. Journal of Clinical Oncology. 2016; 34: TPS5603-TPS.

182. Paik ES, Kim TH, Cho YJ, Ryu J, Choi JJ, Lee YY, et al. Preclinical assessment of the VEGFR inhibitor axitinib as a therapeutic agent for epithelial ovarian cancer. Sci Rep. 2020; 10: 4904.

183. Yamaguchi K, Mandai M, Toyokuni S, Hamanishi J, Higuchi T, Takakura K, et al. Contents of Endometriotic Cysts, Especially the High Concentration of Free Iron, Are a Possible Cause of Carcinogenesis in the Cysts through the Iron-Induced Persistent Oxidative Stress. Clinical Cancer Research An Official Journal of the American Association for Cancer Research. 14: 32-40.

184. Masaki Mandai YA, Ken Yamaguchi, Noriomi Matsumura, Tsukasa Baba and Ikuo Konishi. Ovarian clear cell carcinoma meets metabolism; HNF-1 $\beta$ confers survival benefits through the Warburg effect and ROS reduction. Oncotarget. 2015; 6: 30704-14.

185. Oda K, Hamanishi J, Matsuo K, Hasegawa K. Genomics to immunotherapy of ovarian clear cell carcinoma: Unique opportunities for management. Gynecol Oncol. 2018; 151: 381-9.

186. Liu P, Khurana A, Rattan R, He X, Kalloger S, Dowdy S, et al. Regulation of HSulf-1 expression by variant hepatic nuclear factor 1 in ovarian cancer. Cancer Res. 2009; 69: 4843-50

187. Kornfeld JW, Baitzel C, K?nner AC, Nicholls HT, Vogt MC, Herrmanns K, et al. Obesity-induced overexpression of miR-802 impairs glucose metabolism through silencing of Hnf1b. Nature. 494: 111-5.

188. Lengyel E, Litchfield LM, Mitra AK, Nieman KM, Mukherjee A, Zhang Y, et al. Metformin inhibits ovarian cancer growth and increases sensitivity to paclitaxel in mouse models. Am J Obstet Gynecol. 2015; 212: 479 e1- e10.
189. Disis ML, Taylor MH, Kelly K, Beck JT, Gordon M, Moore KM, et al. Efficacy and Safety of Avelumab for Patients With Recurrent or Refractory Ovarian Cancer: Phase 1b Results From the JAVELIN Solid Tumor Trial. JAMA Oncol. 2019; 5: 393-401.

190. Jung-Min Lee AC-M, Cody J. Peer, Alexandra Zimmer, Stanley Lipkowitz, Christina M. Annunziata, Liang Cao, Maria I. Harrell, Elizabeth M. Swisher, Nicole Houston, Dana-Adriana Botesteanu, Janis M. Taube, Elizabeth Thompson, Aleksandra Ogurtsova, Haiying Xu, Jeffers Nguyen, Tony W. Ho, William D. Figg, and Elise C. Kohn. Safety and Clinical Activity of the Programmed Death-Ligand 1 Inhibitor Durvalumab in Combination With Poly (ADP-Ribose) Polymerase Inhibitor Olaparib or Vascular Endothelial Growth Factor Receptor 1-3 Inhibitor Cediranib in Women's Cancers: A Dose-Escalation, Phase I Study. JOURNAL OF CLINICAL ONCOLOGY. 2017; 35: 2193-202.

191. Matulonis UA, Shapira-Frommer R, Santin AD, Lisyanskaya AS, Pignata S, Vergote I, et al. Antitumor activity and safety of pembrolizumab in patients with advanced recurrent ovarian cancer: results from the phase II KEYNOTE-100 study. Ann Oncol. 2019; 30: 1080-7.

192. Hamanishi J, Mandai M, Ikeda T, Minami M, Konishi I. Safety and Antitumor Activity of Anti-PD-1 Antibody, Nivolumab, in Patients With Platinum-Resistant Ovarian Cancer. Journal of Clinical Oncology Official Journal of the American Society of Clinical Oncology. 2015; 33: 4015-22.

193. Ngoi NY, Heong V, Ow S, Chay WY, Kim HS, Choi CH, et al. A multicenter phase II randomized trial of durvalumab (MEDI-4736) versus physician's choice chemotherapy in recurrent ovarian clear cell adenocarcinoma (MOCCA). Int J Gynecol Cancer. 2020; 30: 1239-42.

194. Willis BC, Sloan EA, Atkins KA, Stoler MH, Mills AM. Mismatch repair status and PD-L1 expression in clear cell carcinomas of the ovary and endometrium. Modern Pathology.

195. Le DT, Durham JN, Smith KN, Wang H, Bartlett BR, Aulakh LK, et al. Mismatch repair deficiency predicts response of solid tumors to PD-1 blockade. Science. 2017; 357: 409-13.

196. Le DT, Uram JN, Wang H, Bartlett BR, Kemberling H, Eyring AD, et al. PD-1 Blockade in Tumors with Mismatch-Repair Deficiency. N Engl J Med. 2015; 372. 2509-20.

197. Suzuki S, Sakata J, Utsumi F, Sekiya R, Kajiyama H, Shibata K, et al. Efficacy of glypican-3-derived peptide vaccine therapy on the survival of patients with refractory ovarian clear cell carcinoma. Oncoimmunology. 2016; 5: e1238542.

198. Takahashi R, Mabuchi S, Kawano M, Sasano T, Matsumoto Y, Kuroda H, et al. Preclinical Investigations of PM01183 (Lurbinectedin) as a Single Agent or in Combination with Other Anticancer Agents for Clear Cell Carcinoma of the Ovary. PLoS One. 2016; 11: e0151050.

199. Sugiyama T, Okamoto A, Enomoto T, Hamano T, Aotani E, Terao Y, et al. Randomized Phase III Trial of Irinotecan Plus Cisplatin Compared With Paclitaxel Plus Carboplatin As First-Line Chemotherapy for Ovarian Clear Cell Carcinoma: JGOG3017/GCIG Trial. J Clin Oncol. 2016; 34: 2881-7.

200. Zou Y, Palte MJ, Deik AA, Li H, Eaton JK, Wang W, et al. A GPX4-dependent cancer cell state underlies the clear-cell morphology and confers sensitivity to ferroptosis. Nat Commun. 2019; 10: 1617.

201. Wakinoue S, Chano T, Amano T, Isono T, Kimura F, Kushima R, et al. ADP-ribosylation factor-like $4 \mathrm{C}$ predicts worse prognosis in endometriosis-associated ovarian cancers. Cancer Biomark. 2019; 24: 223-9.

202. Price C, Gill S, Ho ZV, Davidson SM, Merkel E, McFarland JM, et al. Genome-Wide Interrogation of Human Cancers Identifies EGLN1 Dependency in Clear Cell Ovarian Cancers. Cancer Res. 2019; 79: 2564-79.

203. Rahman MT, Nakayama K, Rahman M, Katagiri H, Katagiri A, Ishibashi T, et al. Fatty acid synthase expression associated with NAC1 is a potential therapeutic target in ovarian clear cell carcinomas. Br J Cancer. 2012; 107: $300-7$.

204. Yoon H, Choi YL, Song JY, Do I, Kang SY, Ko YH, et al. Targeted inhibition of FAK, PYK2 and BCL-XL synergistically enhances apoptosis in ovarian clear cell carcinoma cell lines. PLoS One. 2014; 9: e88587.

205. Mogami T, Yokota N, Asai-Sato M, Yamada R, Koizume S, Sakuma Y, et al. Annexin A4 is involved in proliferation, chemo-resistance and migration and invasion in ovarian clear cell adenocarcinoma cells. PLoS One. 2013; 8: e80359.

206. Arildsen NS, Jonsson JM, Bartuma K, Ebbesson A, Westbom-Fremer S, Masback A, et al. Involvement of Chromatin Remodeling Genes and the Rho GTPases RhoB and CDC42 in Ovarian Clear Cell Carcinoma. Front Oncol. 2017; $7: 109$

207. Guan X-Y, Yanaihara N, Noguchi Y, Saito M, Takenaka M, Takakura S, et al. MicroRNA Gene Expression Signature Driven by miR-9 Overexpression in Ovarian Clear Cell Carcinoma. Plos One. 2016; 11: e0162584.

208. Suh DH, Park JY, Lee JY, Kim BG, Lim MC, Kim JW, et al. The clinical value of surgeons' efforts of preventing intraoperative tumor rupture in stage I clear cell carcinoma of the ovary: A Korean multicenter study. Gynecol Oncol. 2015; 137: $412-7$

209. Prat J, Oncology FCoG. Staging classification for cancer of the ovary, fallopian tube, and peritoneum. Int J Gynaecol Obstet. 2014; 124: 1-5.

210. Kajiyama H, Suzuki S, Yoshihara M, Nishino K, Kikkawa F. The possible existence of occult metastasis in patients with ovarian clear-cell carcinoma who underwent complete resection without any residual tumours. Oncotarget. 2018; 9: 6298-307.

211. Takano M, Kikuchi Y, Yaegashi N, Kuzuya K, Ueki M, Tsuda H, et al. Clear cell carcinoma of the ovary: a retrospective multicentre experience of 254 patients with complete surgical staging. Br J Cancer. 2006; 94: 1369-74. 
212. Nie D, Mao X, Li Z. Prognostic value of lymph nodes ratio in patients with stage III ovarian clear cell carcinoma: A retrospective study of patients in Southwest China. J Cancer. 2019; 10: 4689-94.

213. Oxholm D, Knudsen UB, Kryger-Baggesen N, Ravn P. Postmenopausal endometriosis. Acta Obstet Gynecol Scand. 2007; 86: 1158-64.

214. Van Gorp T, Amant F, Neven P, Vergote I, Moerman P. Endometriosis and the development of malignant tumours of the pelvis. A review of literature. Best Pract Res Clin Obstet Gynaecol. 2004; 18: 349-71.

215. Park J-Y, Kim D-Y, Suh D-S, Kim J-H, Kim Y-M, Kim Y-T, et al. Significance of Ovarian Endometriosis on the Prognosis of Ovarian Clear Cell Carcinoma. International Journal of Gynecologic Cancer. 2018; 28: 11-8.

216. Chang HT, Chiu ML, Wang TY, Chen TC, Chang CL, Su TH, et al. Effect of Chemotherapy, Laparoscopy, and Cytology on Stage IC Ovarian Clear Cell Carcinoma: A Long-Term, Single-Center Study. Int J Environ Res Public Health. 2020; 17.

217. Engqvist H, Parris TZ, Kovacs A, Ronnerman EW, Sundfeldt K, Karlsson P, et al. Validation of Novel Prognostic Biomarkers for Early-Stage Clear-Cell, Endometrioid and Mucinous Ovarian Carcinomas Using Immunohistochemistry. Front Oncol. 2020; 10: 162.

218. Fridley BL, Dai J, Raghavan R, Li Q, Winham SJ, Hou X, et al. Transcriptomic Characterization of Endometrioid, Clear Cell, and High-Grade Serous Epithelial Ovarian Carcinoma. Cancer Epidemiol Biomarkers Prev. 2018; 27: 1101-9.

219. Matsushita $H$, Hasegawa $K$, Oda $K$, Yamamoto $S$, Nishijima A, Imai Y, et al The frequency of neoantigens per somatic mutation rather than overall mutational load or number of predicted neoantigens per se is a prognostic factor in ovarian clear cell carcinoma. Oncoimmunology. 2017; 6: e1338996.

220. Kim J, Chung JY, Hwang JR, Lee YY, Kim TJ, Lee JW, et al. Identification of Candidate Genes Associated with Susceptibility to Ovarian Clear Cell Adenocarcinoma Using cis-eQTL Analysis. J Clin Med. 2020; 9.

221. Amano T, Chano T, Isono T, Kimura F, Kushima R, Murakami T. Abundance of mitochondrial superoxide dismutase is a negative predictive biomarker for endometriosis-associated ovarian cancers. World J Surg Oncol. 2019; 17: 24

222. Crotzer DR, Sun CC, Coleman RL, Wolf JK, Levenback CF, Gershenson DM. Lack of effective systemic therapy for recurrent clear cell carcinoma of the ovary. Gynecol Oncol. 2007; 105: 404-8.

223. Nezhat F, Apostol R, Mahmoud M, el Daouk M. Malignant transformation of endometriosis and its clinical significance. Fertil Steril. 2014; 102: 342-4. 